\title{
Functional characterization of a xylose transporter in Aspergillus nidulans
}

\author{
Ana Cristina Colabardini ${ }^{1}$, Laure Nicolas Annick Ries ${ }^{1}$, Neil Andrew Brown ${ }^{1}$, Thaila Fernanda dos Reis ${ }^{1}$, Marcela Savoldi ${ }^{1}$
} Maria Helena S Goldman², João Filipe Menino ${ }^{3}$, Fernando Rodrigues ${ }^{3}$ and Gustavo Henrique Goldman ${ }^{1,4^{*}}$

\begin{abstract}
Background: The production of bioethanol from lignocellulosic feedstocks will only become economically feasible when the majority of cellulosic and hemicellulosic biopolymers can be efficiently converted into bioethanol. The main component of cellulose is glucose, whereas hemicelluloses mainly consist of pentose sugars such as D-xylose and $\mathrm{L}$-arabinose. The genomes of filamentous fungi such as A. nidulans encode a multiplicity of sugar transporters with broad affinities for hexose and pentose sugars. Saccharomyces cerevisiae, which has a long history of use in industrial fermentation processes, is not able to efficiently transport or metabolize pentose sugars (e.g. xylose). Subsequently, the aim of this study was to identify xylose-transporters from A. nidulans, as potential candidates for introduction into S. cerevisiae in order to improve xylose utilization.

Results: In this study, we identified the A. nidulans xtrD (xylose transporter) gene, which encodes a Major Facilitator Superfamily (MFS) transporter, and which was specifically induced at the transcriptional level by xylose in a XInR-dependent manner, while being partially repressed by glucose in a CreA-dependent manner. We evaluated the ability of $x t r D$ to functionally complement the S. cerevisiae EBY.WW4000 strain which is unable to grow on glucose, fructose, mannose or galactose as single carbon source. In S. cerevisiae, XtrD was targeted to the plasma membrane and its expression was able to restore growth on xylose, glucose, galactose, and mannose as single carbon sources, indicating that this transporter accepts multiple sugars as a substrate. XtrD has a high affinity for xylose, and may be a high affinity xylose transporter. We were able to select a $S$. cerevisiae mutant strain that had increased xylose transport when expressing the xtrD gene.

Conclusions: This study characterized the regulation and substrate specificity of an A. nidulans transporter that represents a good candidate for further directed mutagenesis. Investigation into the area of sugar transport in fungi presents a crucial step for improving the $S$. cerevisiae xylose metabolism. Moreover, we have demonstrated that the introduction of adaptive mutations beyond the introduced xylose utilization genes is able to improve $S$. cerevisiae xylose metabolism.
\end{abstract}

Keywords: Aspergillus nidulans, xylose transporters, Saccharomyces cerevisiae, second generation bioethanol

\section{Background}

Efforts to mitigate global warming and reduce fossil fuel consumption, while sustaining future world-wide energy demands has substantially increased investment in the development of alternative energy sources such as bioethanol.

\footnotetext{
* Correspondence: ggoldman@usp.br

'Departamento de Ciências Farmacêuticas, Faculdade de Ciências

Farmacêuticas de Ribeirão Preto, Universidade de São Paulo, Av. do Café S/N CEP 14040-903 Ribeirão Preto, São Paulo, Brazil

${ }^{4}$ Laboratório Nacional de Ciência e Tecnologia do Bioetanol - CTBE, Caixa

Postal 617013083-970 Campinas, São Paulo, Brazil

Full list of author information is available at the end of the article
}

Currently, bioethanol production throughout the world is based on first-generation technologies (1G) that ferment simple sugars derived from high-sugar-containing plants such as sucrose from sugarbeet or sugarcane and starch from corn. During these processes the remaining carbon locked within the lignocellulosic substrate is not converted into bioethanol. In the case of sugarcane, the waste material, termed bagasse, contains a third of the energy stored within the plant. If bagasse could also be used to produce bioethanol instead of being burnt, production could increase by $40 \%[1,2]$. Thus, the utilization of non-food lignocellulosic plant residues for bioethanol production by 
second-generation technologies $(2 \mathrm{G})$ is extremely attractive for the biofuel industry, representing both economic and environmental gains via reducing the carbon footprint and production costs $[3,4]$.

Lignocellulosic biomass generally consists of cellulose ( $40 \%$ to $50 \%$ ), hemicelluloses ( $25 \%$ to $35 \%$ ) and lignin (15\% to $20 \%$ ) [5]. The objective of $2 \mathrm{G}$ technologies is to dually utilize the hexose and pentose sugars extracted from cellulose and hemicelluloses in the production of bioethanol, therefore making the process economically viable [6,7]. The hexose sugar glucose represents $60 \%$ of the total sugars found in cellulose, whereas hemicellulose is predominantly composed of pentose sugars such as D-xylose and L-arabinose [7]. The conversion of lignocellulose into ethanol, therefore, requires an organism capable of fermenting both hexose and pentose sugars [8]. Saccharomyces cerevisiae is the preferred microbe utilized for industrial fermentation processes including bioethanol production $[9,10]$. Although the $S$. cerevisiae genome appears to encode all components necessary for xylose metabolism, these components are not efficient to allow growth on xylose as the sole carbon source [10].

After xylose is taken up into the cell by the microorganism, it is first converted to xylitol, which is then converted to phosphorylated xylulose prior to generating the pentose phosphate pathway intermediate xylulose-5-phosphate. Xylose reductase (XR) and xylitol dehydrogenase (XDH) catalyze the first two reactions in this pathway and their activity strictly depends on the respective cofactors nicotinamide adenine dinucleotide phosphate (NADPH) and nicotinamide adenine dinucleotide (NAD) ${ }^{+}$. During aerobic respiration, an excess of reduced nicotinamide adenine dinucleotide (NADH) is re-oxidized, but during anaerobic respiration, NADH accumulates in the cell and xylose utilization is slowed down. The XR of the natural xylose-assimilating yeast Scheffersomyces stipitis uses $\mathrm{NADH}$ almost as well as $\mathrm{NADPH}$, avoiding an imbalance of cofactors [9]. Significant efforts have been made to engineer $S$. cerevisiae strains with improved xylose metabolism. Recombinant $S$. cerevisiae strains are able to metabolize xylose and ferment xylulose through the heterologous expression of XR-XDH or other enzymes such as xylose isomerase, a bacterial enzyme that catalyzes the one-way conversion of xylose to xylulose [11-15].

However, another limiting step in the utilization of xylose by $S$. cerevisiae is the transport of xylose into the cell. Domestic and wild-type $S$. cerevisiae species transport xylose into the cell with low-affinity $\left(K_{M}=100 \mathrm{mM}\right.$ to $\left.190 \mathrm{mM}\right)$ via the expression of native high-affinity hexose transporters, such as GAL2 and HXT7 [7,16]. A functional survey of the expression of heterologous sugar transporters in recombinant $S$. cerevisiae evaluated 26 monosaccharide transporters. Ten of these transporters conferred growth on individual sugars, while the majority exhibited a broad substrate range, with all of them favoring glucose transport when in competition with other monosaccharides. Glucose has previously been shown to inhibit xylose transport $[7,10]$. Therefore, heterologous expression of a specific xylose transporter, especially those transporting xylose with higher affinity than glucose $[7,10]$, is indispensable for improved xylose utilization in recombinant $S$. cerevisiae. Alternatively, transporter proteins can be engineered through introducing mutations, in order to have increased xylose transport in S. cerevisiae $[7,10]$.

In contrast to $S$. cerevisiae, filamentous fungi are specialized in lignocellulosic biomass degradation and through the secretion of a large repertoire of hydrolytic enzymes, the sugar polymers are broken down into simple sugars which are subsequently taken up into the cell $[17,18]$. The genomes of filamentous fungi also encode large numbers of sugar transporters. However, very few fungal sugar transporters have been functionally characterized. Aspergilli are a group of filamentous fungi capable of producing a wide variety of plant biomass-degrading enzymes and can grow on lignocellulose. In Aspergilli the lignocellulose utilization pathway is tightly repressed by the transcription factor CreA that mediates carbon catabolite repression (CCR) and positively induced by the regulon-specific transcription factors $\mathrm{XlnR}, \mathrm{ClrA}$, and $\mathrm{ClrB}[17,18]$. The aim of this study was therefore to identify xylose transporter-encoding genes in Aspergillus nidulans that are potential candidates for heterologous gene expression in S. cerevisiae. We identified the A. nidulans xtrD (xylose transporter) gene, encoding a transporter from the major facilitator superfamily (MFS). Induction of $x \operatorname{tr} D$ at the transcriptional level was observed in the presence of xylose in an XlnR-dependent manner. We also showed that in $A$. nidulans $x \operatorname{tr} D$ is repressed by glucose in a CreA-dependent manner. To further characterize the protein encoded by $x \operatorname{tr} D$, we expressed the gene in a $S$. cerevisiae strain that is unable to grow on glucose, fructose, mannose or galactose as a single carbon source. In S. cerevisiae XtrD was targeted to the plasma membrane and its expression was able to restore growth on xylose, glucose, galactose, and mannose as single carbon sources, indicating that this transporter accepts multiple sugars as a substrate. This work identified an efficient xylose transporter which could potentially be used in future studies to improve $S$. cerevisiae xylose uptake through site-directed mutagenesis, directed evolution or in combination with other heterologous transporters.

\section{Results}

\section{Xylose metabolism is partially repressed by glucose}

Initially to establish the parameters for the induction of xylose transporters and xylose uptake, the $A$. nidulans wild-type and carbon catabolite resistant creAd30 strains were grown on xylose as a sole carbon source or in media 
containing both xylose and glucose. The A. nidulans cultures were first grown on fructose and then transferred to media containing $1 \%$ xylose or media containing $1 \%$ xylose plus $1 \%$ glucose for 6,12 and 24 h (Figure 1). The endoxylanase activity of the supernatant was recorded for both strains during all time points (Figure 1A). In the wild-type strain, xylose clearly induced the secretion of endoxylanases, whereas the simultaneous presence of xylose and glucose reduced endoxylanase production (Figure 1A). On the other hand, in the creAd30 strain no such difference was observed between the xylose and the xylose plus glucose cultures for most time points (Figure 1A). Also, the creAd30 mutant secreted more endoxylanases than the wild-type strain (Figure 1A). In order to know whether this observation depends on the amount of internalized xylose and glucose in both strains, the concentration of the respective sugars in the extracellular media was determined (Figure $1 \mathrm{~B}$ and $1 \mathrm{C}$ ). The rate of xylose uptake was faster in the wild-type strain than in the creAd30 mutant when grown on xylose as a sole carbon source (Figure 1B). During growth of the wild-type strain in the simultaneous presence of xylose and glucose, a high concentration of xylose persisted in the extracellular medium (Figure 1B). In contrast, in the carbon catabolite derepressed creAd30-strain xylose was taken up even in the presence of glucose (Figure 1B), whereas glucose uptake was slightly slower in the creAd30 strain (Figure 1C). Therefore, $A$. nidulans preferentially takes up glucose, with xylose transport and metabolism being partially subjected to $\mathrm{CCR}$.

\section{Transcriptional profiling of $A$. nidulans in the presence of xylose}

Genome-wide transcriptional profiling was utilized to identify the genes and pathways involved in xylose transport and metabolism. The A. nidulans wild-type strain was grown in media containing $1 \%$ fructose (reference) and then transferred to media containing $1 \%$ xylose for 6 ,

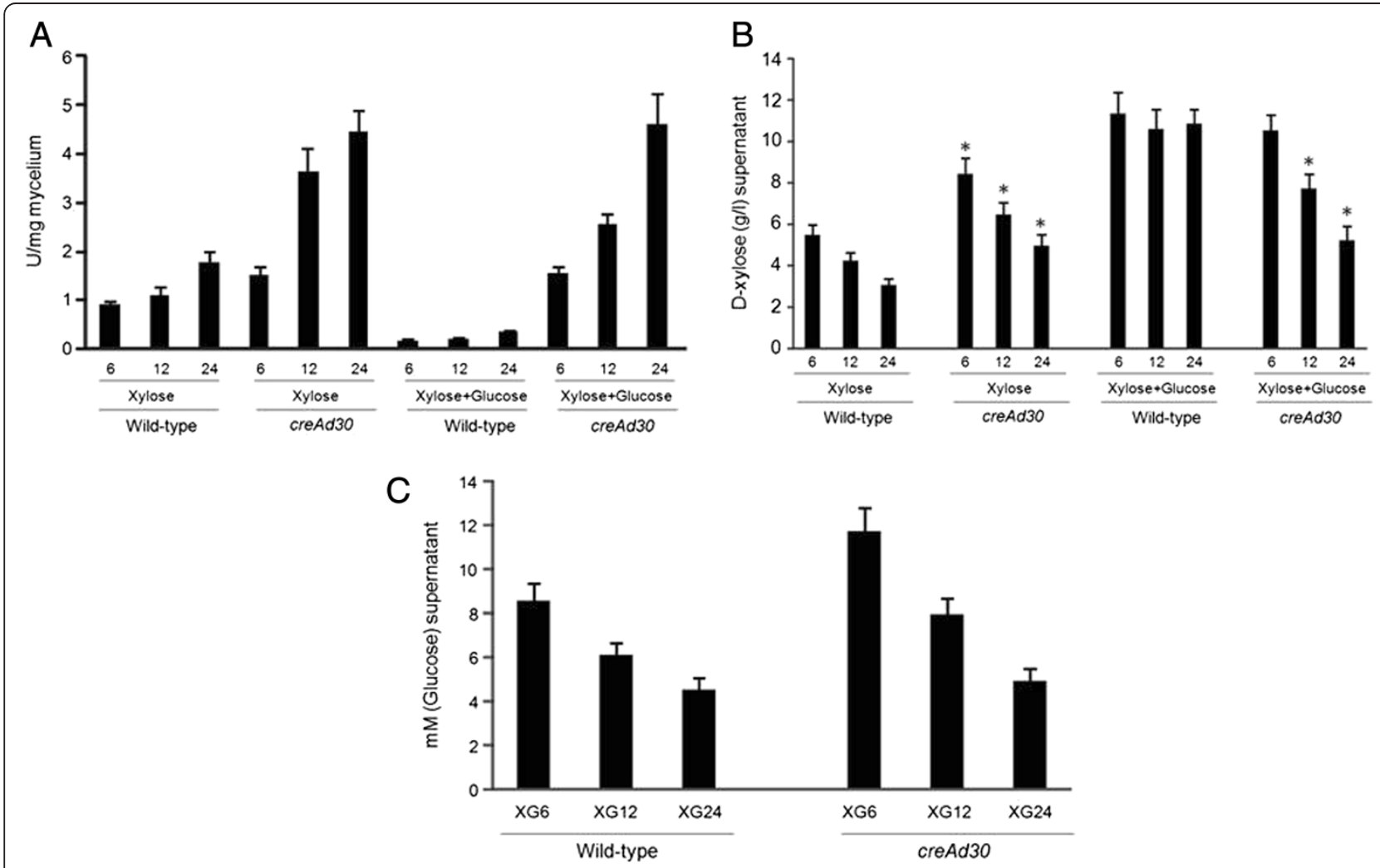

Figure 1 A. nidulans growth in the presence of xylose or xylose plus glucose. (A) Enzymatic activity of endo-1,4- $\beta$-xylanase in the culture supernatant in the presence of xylose $(X)$ or xylose plus glucose $(X G)$ after $6 \mathrm{~h}, 12 \mathrm{~h}$ and $24 \mathrm{~h}$ incubation at $37^{\circ} \mathrm{C}$. One unit of enzyme activity is defined as the amount of enzyme required to release $1 \mu \mathrm{mol}$ of $\mathrm{D}$-xylose reducing-sugar equivalents from arabinoxylan, at pH $4.5 \mathrm{per}$ minute at $40^{\circ} \mathrm{C}$. Error bars represent the standard deviation for three biological replicates; ${ }^{*}$ significant difference in the $P$-value $(<0.01$, one-way analysis of variance (anova) and Newman-Keuls test) between $\mathrm{X}$ and XG-grown cultures for each strain. (B) Xylose concentrations in the supernatant of $A$. nidulans wild-type and creAd30 cultures grown in the presence of xylose $(X)$ or xylose plus glucose $(X G)$ for $6 \mathrm{~h}, 12 \mathrm{~h}$, and $24 \mathrm{~h}$ at $37^{\circ} \mathrm{C}$. (C) Glucose concentrations in the supernatant of A. nidulans wild-type and creAd30 cultures grown in the presence of xylose or xylose plus glucose for $6 \mathrm{~h}, 12 \mathrm{~h}$ and $24 \mathrm{~h}$ at $37^{\circ} \mathrm{C}$. Error bars represent the standard deviation for three biological replicates; ${ }^{*}$ significant difference in the $P$-value $(<0.01$, one-way Anova and Newman-Keuls test) between $X$ and $X G$-grown cultures for each strain. 
12 and $24 \mathrm{~h}$. The main objective was to identify genes with increased expression in xylose when compared to the control condition. In total 1,558 genes were differentially expressed $(P<0.01)$ in at least one time point (GSE50485; see Additional file 1). The proteins encoded by differentially expressed genes were classified into FunCat functional categories (http://mips.helmholtz-muenchen.de/ proj/funcatDB/search_main_frame.html), revealing a wide variety of cellular processes. Hierarchical clustering allowed the classification of these genes into four main clusters (Figure 2A), where genes from clusters $\mathrm{C} 1$ and $\mathrm{C} 2$ were induced, whilst genes from clusters $\mathrm{C} 3$ and $\mathrm{C} 4$ were repressed, during growth on xylose. All four clusters were enriched $(P<0.001)$ in genes encoding proteins with functions in metabolism, signal transduction mechanisms, interaction with the environment, and energy (Figures $2 \mathrm{~B}$ and 2C).

As expected, there was high upregulation of genes involved in xylose metabolism, such as D-xylose reductase (AN9064), xylitol dehydrogenase (AN9064) and xylulokinase (AN8790). In addition, there was an induction of xylanases and other plant cell-wall-degrading enzymeencoding genes (Tables 1 and 2). The differentially expressed genes that encode putative transporters and transcription factors are shown in Table 3. One of these genes is $a b a A$, which encodes a transcriptional activator involved in the regulation of conidiation and which is required for phialide differentiation [20] (Table 3). We did not observe any conidiation in our cultures (data not shown) and it remains to be investigated whether $a b a A$ plays a role in gene regulation during growth of $A$. nidulans in the presence of xylose. Multiple transporterencoding genes resided in cluster $\mathrm{C} 1$ and were highly upregulated when $A$. nidulans mycelia were transferred to xylose containing media (Table 3 ). Among the several putative transporters, we randomly selected five transporterencoding genes for further study (AN6412 (xtrA), AN3264 ( $x \operatorname{tr} B)$, AN2358 ( $x \operatorname{trC})$, AN0250 ( $x \operatorname{trD})$ and AN4148 ( $x$ trE)). The induction of the five transporter encoding genes was confirmed by RT-qPCR. All five genes were induced to a different extent in the presence of xylose and repressed in the presence of glucose (Table 4). Therefore, xylose-specific expression profiling has identified several $A$. nidulans transporter-encoding genes, which may represent potential xylose transporters.

\section{Functional characterization of genes encoding putative xylose transporters}

In order to further characterize the five candidate xylose transporters, their expression patterns during growth in the presence of various carbon sources were measured by RT-qPCR (Figure 3). A. nidulans was grown from conidia

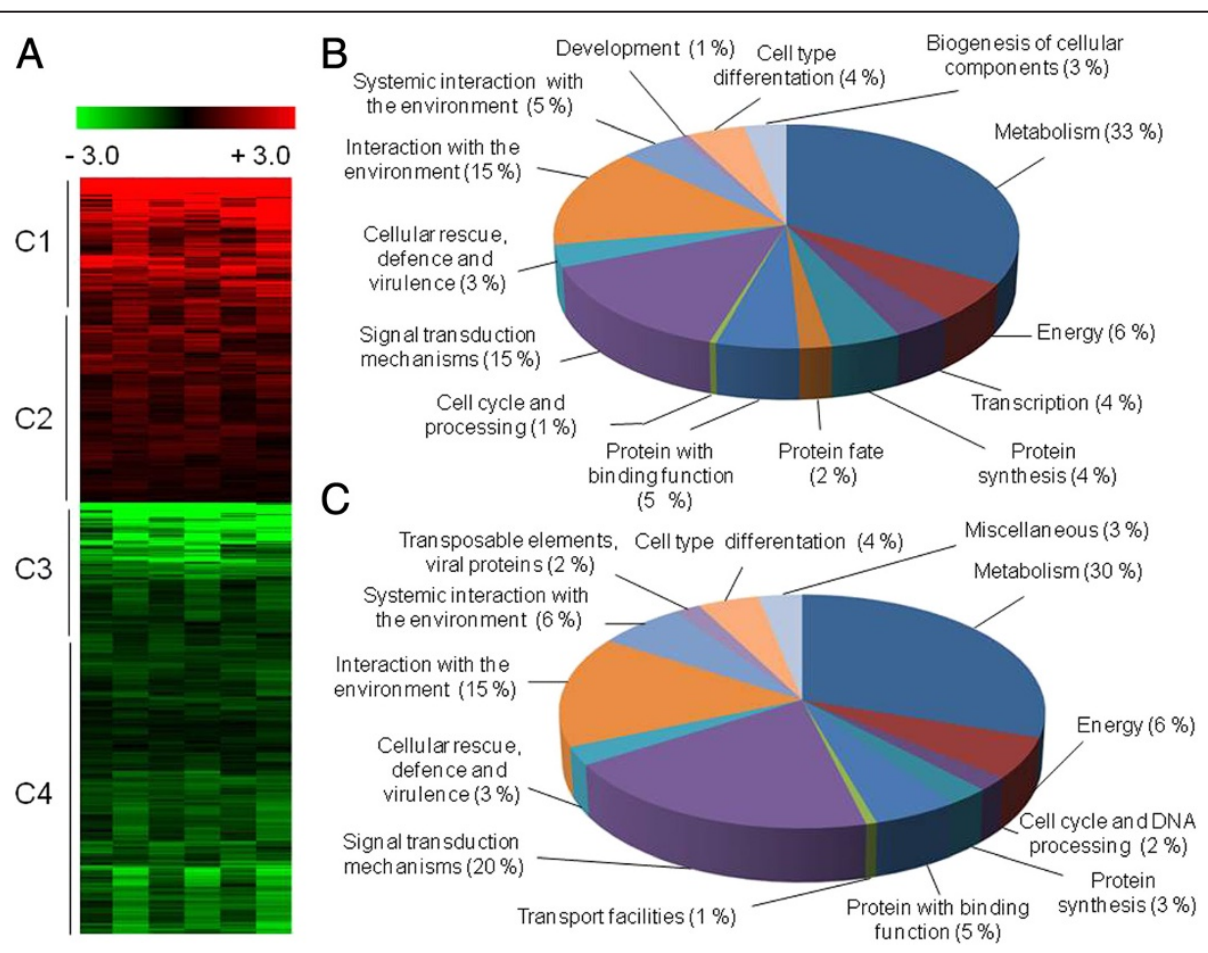

Figure 2 Gene expression patterns of $\boldsymbol{A}$. nidulans wild-type cultures grown in the presence of xylose. (A) Microarray results: the color code (red $=$ expression, green $=$ repression) displays the $\log _{2}(\mathrm{Cy} 5 / \mathrm{Cy} 3)$ value for each time point with $\mathrm{Cy} 3$ as the reference value (time point $=0$, growth on fructose). The data were visualized based on similar expression vectors using Euclidean distance and hierarchical clustering with average linkage clustering and classed into four clusters (C1 to C4). (B, C) Classification of genes from (A) into the respective FunCat categories [19]. 
Table 1 Differentially expressed genes, predicted to encode proteins involved in carbon metabolism, between $24 \mathrm{~h}$ fructose and $6 \mathrm{~h}, 12 \mathrm{~h}$ and $24 \mathrm{~h}$ xylose in A. nidulans

\begin{tabular}{|c|c|c|c|c|c|}
\hline Function & ID & Description & $\begin{array}{c}6 \mathrm{~h} \\
\log _{2} \text { Cy5/Cy3 }\end{array}$ & $\begin{array}{c}12 \mathrm{~h} \\
\log _{2} \text { Cy5/Cy3 }\end{array}$ & $\begin{array}{c}24 \mathrm{~h} \\
\log _{2} \text { Cy5/Cy3 }\end{array}$ \\
\hline \multicolumn{6}{|c|}{ C1 category } \\
\hline$x y r A$ & AN0423 & Putative D-xylose reductase & 7.75 & 7.36 & 7.17 \\
\hline$a c u D$ & AN5634 & Isocitrate lyase & 1.90 & 1.68 & 2.24 \\
\hline$g f d B$ & AN6792 & $\begin{array}{l}\text { Putative NAD + dependent glycerol 3-phosphate } \\
\text { dehydrogenase }\end{array}$ & 1.30 & 1.93 & 1.32 \\
\hline maeA & AN6168 & Putative malate dehydrogenase & 2.05 & 2.12 & 2.19 \\
\hline AN0443 & AN0443 & Alcohol dehydrogenase & 1.16 & 0.65 & 0.99 \\
\hline AN1274 & AN1274 & $\begin{array}{l}\text { Alditol:NADP }{ }^{+} \text {oxidoreductase; role in arabinose and xylose } \\
\text { catabolic process }\end{array}$ & 3.98 & 3.11 & 2.81 \\
\hline AN2099 & AN2099 & alternative oxidase AoxA & 2.03 & 1.36 & 2.21 \\
\hline AN2951 & AN2951 & $\begin{array}{l}\text { Putative UDP-glucose 4-epimerase; role in } \\
\text { galactose and galactitol metabolism }\end{array}$ & 1.07 & 1.06 & 2.01 \\
\hline AN3432 & AN3432 & $\begin{array}{l}\text { Putative epimerase with a predicted role } \\
\text { in carbohydrate metabolism }\end{array}$ & 3.84 & 3.43 & 3.57 \\
\hline AN7343 & AN7343 & Amylase cluster transcriptional regulator AmyR & 1.21 & 0.80 & 1.41 \\
\hline AN8790 & AN8790 & Putative xylulokinase & 2.28 & 1.82 & 1.51 \\
\hline AN9031 & AN9031 & Fumarylacetoacetate hydrolase & 1.25 & 1.04 & 1.34 \\
\hline AN9064 & AN9064 & Xylitol dehydrogenase & 3.49 & 2.68 & 2.37 \\
\hline AN9152 & AN9152 & NAD dependent epimerase/dehydratase family protein & 1.50 & 0.96 & 2.14 \\
\hline AN9457 & AN9457 & L-galactose dehydrogenase & 6.05 & 4.58 & 4.86 \\
\hline \multicolumn{6}{|c|}{ C2 category } \\
\hline ladC & AN8552 & L-arabinitol 4-dehydrogenase (PPP) & 0.32 & 0.15 & 0.17 \\
\hline orlA & AN3441 & Trehalose 6-phosphate phosphatase & 0.68 & 0.39 & 0.37 \\
\hline ugeA & AN4727 & UDP-glucose 4-epimerase & 0.78 & 1.07 & 0.54 \\
\hline AN10783 & AN10783 & 6-phosphogluconate dehydrogenase family protein & 0.99 & 1.15 & 0.62 \\
\hline AN2470 & AN2470 & Alcohol dehydrogenase & 0.79 & 0.66 & 1.13 \\
\hline AN7588 & AN7588 & Putative ribulose-phosphate 3-epimerase (PPP) & 0.79 & 0.39 & 0.58 \\
\hline AN8707 & AN8707 & $\begin{array}{l}\text { Putative fumarate dehydratase with a predicted } \\
\text { role in the TCA cycle }\end{array}$ & 0.60 & 0.46 & 0.13 \\
\hline AN9347 & AN9347 & Alcohol dehydrogenase & 0.76 & 0.60 & 1.02 \\
\hline \multicolumn{6}{|c|}{ C3 category } \\
\hline $\mathrm{aco} A$ & AN5525 & $\begin{array}{l}\text { Putative aconitate hydratase with a predicted } \\
\text { role in the TCA cycle }\end{array}$ & -0.62 & -0.66 & -0.55 \\
\hline alcs & AN8981 & Protein with homology to GPR1/FUN34/YaaH family members & -2.80 & -2.73 & -2.85 \\
\hline $\operatorname{carC}$ & AN8793 & Putative succinate dehydrogenase (ubiquinone) & -0.40 & -0.31 & -0.52 \\
\hline galF & AN9148 & Putative UTP-glucose-1-phosphate uridylyltransferase & -0.48 & -0.20 & -0.54 \\
\hline gpgA & AN2742 & $\begin{array}{l}\text { Gamma subunit of a heterotrimeric } G \text { protein } \\
\text { composed of FadA }\end{array}$ & -0.34 & -0.36 & -0.42 \\
\hline gprC & AN3765 & Putative G-protein coupled receptor & -1.59 & -2.83 & -3.14 \\
\hline gsdA & AN2981 & Putative glucose 6-phosphate 1-dehydrogenase (PPP) & -0.49 & -0.55 & -0.88 \\
\hline idpA & AN2999 & $\begin{array}{l}\text { Isocitrate dehydrogenase (NADP+) with a predicted } \\
\text { role in the TCA cycle }\end{array}$ & -0.96 & -1.10 & -0.91 \\
\hline mcsA & AN6650 & Methylcitrate synthase with a predicted role in the TCA cycle & -1.31 & -1.05 & -2.05 \\
\hline mdhA & AN6717 & Putative malate dehydrogenase with a predicted role in the & -0.48 & -0.41 & -0.51 \\
\hline
\end{tabular}


Table 1 Differentially expressed genes, predicted to encode proteins involved in carbon metabolism, between $24 \mathrm{~h}$ fructose and $6 \mathrm{~h}, 12 \mathrm{~h}$ and $24 \mathrm{~h}$ xylose in A. nidulans (Continued)

\begin{tabular}{|c|c|c|c|c|c|}
\hline pycA & AN4462 & Putative pyruvate carboxylase or glutathione synthase & -0.34 & -0.20 & -0.66 \\
\hline sfaD & AN0081 & Beta subunit of a heterotrimeric $G$ protein composed of FadA & -0.40 & -0.52 & -0.61 \\
\hline tpiA & AN6900 & $\begin{array}{l}\text { Putative triose-phosphate isomerase with a role } \\
\text { in gluconeogenesis and glycolysis }\end{array}$ & -0.71 & -0.74 & -0.66 \\
\hline vmaB & AN6232 & $\begin{array}{l}\text { Putative F1F0-ATPase complex subunit with a predicted } \\
\text { role in energy metabolism }\end{array}$ & -0.83 & -0.86 & -0.90 \\
\hline AN0252 & AN0252 & $\begin{array}{l}\text { Putative F1F0-ATPase complex subunit with a predicted } \\
\text { role in energy metabolism }\end{array}$ & -0.69 & -0.54 & -0.70 \\
\hline AN0567 & AN0567 & $\begin{array}{l}\text { Putative alcohol oxidase with a predicted role } \\
\text { in glycerol metabolism }\end{array}$ & -2.13 & -1.77 & -2.73 \\
\hline AN0896 & AN0896 & Putative succinate dehydrogenase & -0.78 & -0.64 & -0.66 \\
\hline AN1534 & AN1534 & $\begin{array}{l}\text { Putative F1F0-ATPase complex subunit with a predicted } \\
\text { role in energy metabolism }\end{array}$ & -0.53 & -0.52 & -0.44 \\
\hline AN2208 & AN2208 & Putative galactose 1-dehydrogenase & -0.65 & -0.85 & -0.97 \\
\hline AN2315 & AN2315 & $\begin{array}{l}\text { Putative F1F0-ATPase complex subunit with a predicted } \\
\text { role in energy metabolism }\end{array}$ & -0.47 & -0.43 & -0.57 \\
\hline AN2316 & AN2316 & $\begin{array}{l}\text { Putative cytochrome c oxidase subunit with a predicted } \\
\text { role in energy metabolism }\end{array}$ & -0.61 & -0.52 & -0.52 \\
\hline AN2815 & AN2815 & $\begin{array}{l}\text { Putative mannitol 2-dehydrogenase with a predicted } \\
\text { role in mannose/mannitol }\end{array}$ & -0.62 & -0.91 & -0.45 \\
\hline AN3088 & AN3088 & $\begin{array}{l}\text { Putative F1F0-ATPase complex subunit with a predicted } \\
\text { role in energy metabolism }\end{array}$ & -0.39 & -0.40 & -0.27 \\
\hline AN4525 & AN4525 & $\begin{array}{l}\text { Putative cytochrome c oxidase subunit with a predicted } \\
\text { role in energy metabolism }\end{array}$ & -0.68 & -0.74 & -0.55 \\
\hline AN5629 & AN5629 & $\begin{array}{l}\text { Putative NADH dehydrogenase (ubiquinone) with a predicted } \\
\text { role in energy metabolism }\end{array}$ & -0.45 & -0.52 & -0.73 \\
\hline AN5703 & AN5703 & $\begin{array}{l}\text { Electron-transferring-flavoprotein dehydrogenase with } \\
\text { a predicted role in energy metabolism }\end{array}$ & -0.44 & -0.50 & -0.56 \\
\hline AN5907 & AN5907 & Putative ribose-5-phosphate isomerase & -0.96 & -1.00 & -1.13 \\
\hline AN6077 & AN6077 & Putative NADH dehydrogenase (ubiquinone) & -0.52 & -0.56 & -0.53 \\
\hline AN6287 & AN6287 & $\begin{array}{l}\text { F1F0-ATPase complex subunit with a predicted role } \\
\text { in energy metabolism }\end{array}$ & -0.59 & -0.59 & -0.59 \\
\hline AN8118 & AN8118 & $\begin{array}{l}\text { Putative cytochrome c oxidase subunit with a predicted } \\
\text { role in energy metabolism }\end{array}$ & -0.54 & -0.57 & -0.36 \\
\hline AN8273 & AN8273 & Putative ubiquinol-cytochrome-c reductase & -0.69 & -0.87 & -0.73 \\
\hline AN8819 & AN8819 & $\begin{array}{l}\text { Putative dehydrogenase with a predicted role in } \\
\text { carbohydrate metabolism }\end{array}$ & -0.90 & -1.03 & -1.09 \\
\hline
\end{tabular}

for $8 \mathrm{~h}$ or $16 \mathrm{~h}$ in media supplemented with glucose, sorbitol, xylose, fructose, maltose or galactose. Genes $x \operatorname{tr} A,-B,-C$, and $-E$ were induced to a different extent in the presence of all carbon sources. The expression levels of $x \operatorname{tr} A, x \operatorname{tr} B$ and $x \operatorname{tr} E$ increased in the presence of fructose, maltose, galactose and mannose (Figures 3A, $3 \mathrm{~B}$ and $3 \mathrm{E}$ ), whereas $x \operatorname{tr} C$ mRNA levels increased in the presence of sorbitol, fructose and maltose (Figure $3 \mathrm{C}$ ). The only gene with increased expression levels only in the presence of xylose was $x \operatorname{trD}$ (Figure 3D). In order to understand the transcriptional regulation of this gene and the sub-cellular location of the XtrD protein, an XtrD::GFP strain was constructed. All phenotypic traits of this strain were identical to the wild-type strain (data not shown). The XtrD::GFP strain was germinated for $8 \mathrm{~h}$ in media containing $0.5 \%$ or $2 \%$ xylose. A weak fluorescent signal was observed in the XtrD::GFP strain after $1 \mathrm{~h}$ in the presence of both $0.5 \%$ and $2 \%$ xylose. This fluorescence increased considerably after $2 \mathrm{~h}$ in the presence of the same xylose concentrations (Figure 4). During the $6 \mathrm{~h}$ to $8 \mathrm{~h}$ incubation in xylose-rich media (0.5\% and 2\%), XtrD::GFP was mainly observed at the cell membrane and in a few small spots within the cell (2\%), which appear to be vesicles (Figure 4). No fluorescence was observed in glucose-grown cultures at any time point. When incubated in the presence of several other carbon sources, including arabinose and other hexoses, no XtrD:: GFP fluorescence was observed (data not shown). This 
Table 2 Differentially expressed genes, encoding plant cell-wall-degrading enzymes, between $24 \mathrm{~h}$ fructose and $6 \mathrm{~h}$, $12 \mathrm{~h}$ and $24 \mathrm{~h}$ xylose in $A$. nidulans

\begin{tabular}{|c|c|c|c|c|c|}
\hline Function & ID & Description & $\begin{array}{c}6 \mathrm{~h} \\
\log _{2} \text { Cy5/Cy3 }\end{array}$ & $\begin{array}{c}12 \mathrm{~h} \\
\log _{2} \text { Cy5/Cy3 }\end{array}$ & $\begin{array}{c}24 \mathrm{~h} \\
\log _{2} \text { Cy5/Cy3 }\end{array}$ \\
\hline \multicolumn{6}{|c|}{ C1 category } \\
\hline $\mathrm{afcC}$ & AN10376 & Putative alpha-fucosidase & 2.08 & 1.26 & 1.60 \\
\hline aguA & AN9286 & Protein with alpha-glucuronidase activity & 3.48 & 3.85 & 2.34 \\
\hline AN0280 & AN0280 & Putative alpha-1,4-glucosidase & 4.34 & 4.86 & 4.79 \\
\hline AN0551 & AN0551 & Putative mannosyl-oligosaccharide 1,2-alpha-mannosidase & 0.72 & 0.77 & 1.45 \\
\hline AN10375 & AN10375 & Beta-glucosidase & 4.63 & 3.91 & 2.35 \\
\hline AN2533 & AN2533 & Putative alpha-L-arabinofuranosidase & 1.10 & 2.19 & 1.26 \\
\hline AN8369 & AN8369 & Glycosyl transferase, group 1 family protein & 1.27 & 0.75 & 1.39 \\
\hline AN8477 & AN8477 & Putative beta-1,4-xylosidase & 4.41 & 4.42 & 2.75 \\
\hline axeA & AN6093 & Protein with acetylxylan esterase activity & 3.11 & 3.19 & 2.86 \\
\hline $\operatorname{axhA}$ & AN7908 & Protein with alpha-arabinofuranosidase activity & 5.26 & 4.94 & 5.70 \\
\hline bxIC & AN1477 & Putative beta-1,4-xylosidase & 5.62 & 5.43 & 5.07 \\
\hline bxIC & AN2217 & Putative beta-1,4-xylosidase & 1.44 & 1.21 & 0.39 \\
\hline$b x \mid D$ & AN7864 & Putative beta-1,4-xylosidase & 5.98 & 6.00 & 6.11 \\
\hline dfgB & AN8421 & Putative endo-mannanase GH76 family protein & 1.43 & 2.05 & 2.21 \\
\hline$x \ln A$ & AN3613 & Protein with endo-1,4-beta-xylanase activity & 5.50 & 5.70 & 6.48 \\
\hline$x \ln B$ & AN9365 & Protein with endo-1,4-beta-xylanase activity & 4.03 & 3.99 & 2.85 \\
\hline$x \ln C$ & AN1818 & Endo-1,4-beta-xylanase activity & 6.87 & 7.01 & 6.54 \\
\hline$x \ln D$ & AN2359 & Protein with beta-xylosidase & 5.22 & 5.13 & 5.52 \\
\hline \multicolumn{6}{|c|}{ C2 category } \\
\hline AN3740 & AN3740 & Amidohydrolase family protein & 0.91 & 0.85 & 0.95 \\
\hline AN5748 & AN5748 & Putative mannosyl-oligosaccharide & 0.36 & 0.32 & 0.35 \\
\hline AN10124 & AN10124 & Beta-glucosidase, putative & 0.63 & 0.52 & 0.74 \\
\hline agdD & AN7505 & Protein with alpha-xylosidase activity & 1.00 & 0.59 & 0.81 \\
\hline bglQ & AN10127 & Putative beta-glucosidase & 0.62 & 0.83 & 0.36 \\
\hline pelB & AN2569 & Protein with pectin lyase activity & 0.88 & 0.81 & 0.92 \\
\hline pmeA & AN3390 & Protein with pectinesterase activity & 0.40 & 0.70 & 0.58 \\
\hline \multicolumn{6}{|c|}{ C3 category } \\
\hline $\operatorname{agdB}$ & AN8953 & Alpha-glucosidase with a predicted role in maltose metabolism & -3.62 & -3.34 & -4.09 \\
\hline $\operatorname{exg} A$ & AN1332 & Putative glycosyl hydrolase, GH5 & -0.50 & -1.27 & -1.79 \\
\hline gelB & AN0558 & Putative glycosyl hydrolase, GH72 & -0.81 & -1.01 & -1.04 \\
\hline
\end{tabular}

indicates that $x \operatorname{tr} D$ was transcriptionally induced and translated specifically upon the detection of the pentose sugar xylose. In addition, the expression profile of $x \operatorname{tr} D$ in the $\triangle X \ln R$ and $\triangle c r e A 4$ strains suggests that $x \operatorname{tr} D$ xylose induction and glucose repression occurred in an XlnRdependent and partially in a CreA-dependent manner (Figure 5).

Subsequently, the roles played by the five transporterencoding genes in carbon source uptake were elucidated by generating $A$. nidulans $x$ tr $A-E$-null mutants using an in vivo $S$. cerevisiae fusion-based approach (see
Methods). Several primary transformed colonies that had homologous integration of $p y r G$ at the $x t r A-E$ loci (confirmed by PCR) were isolated, and one colony for each gene was selected for further analysis. The growth of the null mutant strains and the wild-type strain (control) was monitored on minimal media agar supplemented with one of the following carbon sources: glucose, xylose, maltose, glycerol, mannose, fructose, acetate, rhamnose, casein, carboxymethylcellulose $(\mathrm{CMC})$, inulin, guar, peptone and pectin at $30^{\circ} \mathrm{C}, 37^{\circ} \mathrm{C}$ and $44^{\circ} \mathrm{C}$. The five deletion strains showed the same 
Table 3 Differentially expressed genes, encoding putative transporters and transcription factors, between $24 \mathrm{~h}$ fructose and $6 \mathrm{~h}, 12 \mathrm{~h}$ and $24 \mathrm{~h}$ xylose in A. nidulans

\begin{tabular}{|c|c|c|c|c|}
\hline Function/ID & Description & $\begin{array}{c}6 \mathrm{~h} \\
\log _{2} \text { Cy5/Cy3 }\end{array}$ & $\begin{array}{c}12 \mathrm{~h} \\
\log _{2} \text { Сy5/Сy3 }\end{array}$ & $\begin{array}{c}24 \mathrm{~h} \\
\log _{2} C y 5 / C y 3\end{array}$ \\
\hline \multicolumn{5}{|c|}{ Transporters (C1 category) } \\
\hline AN0250 & Major facilitator superfamily (MFS) sugar transporter & 5.75 & 5.05 & 6.05 \\
\hline AN0332 & MFS transporter & 2.90 & 1.40 & 1.25 \\
\hline AN0601 & MFS transporter & 1.63 & 1.01 & 1.84 \\
\hline AN2358 & MFS protein & 1.84 & 1.75 & 2.11 \\
\hline AN2746 & MFS monocarboxylate transporter & 1.31 & 0.48 & 1.31 \\
\hline AN2959 & MFS transporter & 0.75 & 1.45 & 1.70 \\
\hline AN3264 & MFS transporter & 2.84 & 1.63 & 4.13 \\
\hline AN4148 & MFS monosaccharide transporter & 2.94 & 3.32 & 3.39 \\
\hline AN4374 & MFS transporter & 0.72 & 1.28 & 1.36 \\
\hline AN6412 & MFS transporter & 1.90 & 1.66 & 2.90 \\
\hline AN6779 & $A B C$ transporter & 1.44 & 1.29 & 0.68 \\
\hline AN8347 & Hexose transporter protein & 5.97 & 5.81 & 6.08 \\
\hline AN9165 & MFS transporter & 1.70 & 2.22 & 2.32 \\
\hline AN9173 & MFS glucose transporter & 2.38 & 1.52 & 1.66 \\
\hline \multicolumn{5}{|c|}{$\begin{array}{l}\text { Transcription factors (C1 } \\
\text { category) }\end{array}$} \\
\hline AN0273 & $\mathrm{C} 2 \mathrm{H} 2$ type zinc finger domain-containing protein & 0.77 & 0.93 & 1.37 \\
\hline AN0422 & abaA; TEA/ATTS domain transcriptional activator & 4.48 & 4.22 & 4.15 \\
\hline AN11169 & C6 transcription factor & 0.86 & 0.90 & 1.27 \\
\hline AN1729 & $\begin{array}{l}\text { prnA; Transcriptional activator from the zinc binuclear } \\
\text { cluster family }\end{array}$ & 1.08 & 0.68 & 1.29 \\
\hline AN7170 & HLH DNA binding domain protein & 1.00 & 0.59 & 0.98 \\
\hline AN7343 & amylase cluster transcriptional regulator AmyR & 1.21 & 0.80 & 1.41 \\
\hline \multicolumn{5}{|c|}{ Transporters (C3 category) } \\
\hline AN0010 & Putative amino acid transporter & -1.74 & -3.76 & -1.67 \\
\hline AN1797 & S. cerevisiae ortholog RGT2 has role in glucose transport & -0.42 & -1.35 & -1.22 \\
\hline \multicolumn{5}{|c|}{$\begin{array}{l}\text { Transcription factors (C3 } \\
\text { category) }\end{array}$} \\
\hline AN2016 & amyR; Zn (2)Cys (6) TF involved in starch metabolism & -1.55 & -1.68 & -1.89 \\
\hline
\end{tabular}

Table 4 Expression values (as determined by qRT-PCR) for the five transporter-encoding xtrA-E genes when $A$. nidulans was grown in fructose for $\mathbf{2 4} \mathrm{h}$ and then transferred to xylose (X) or xylose and glucose (X+G)-rich media for 6 h, 12 h and $24 \mathrm{~h}$

\begin{tabular}{lccccccc}
\hline & Control & X6 & X + G6 & X12 & X+G12 & X24 & X+G24 \\
\hline $\boldsymbol{x t r A ~ ( A N 6 4 1 2 ) ~}$ & $0.55 \pm 0.04$ & $0.42 \pm 0.06$ & $0.70 \pm 0.16$ & $4.14 \pm 0.21$ & $0.66 \pm 0.09$ & $7.03 \pm 0.35$ & $1.71 \pm 0.02$ \\
$\boldsymbol{x t r B}$ (AN3264) & $0.003 \pm 0.002$ & $0.003 \pm 0.00$ & $0.010 \pm 0.002$ & $0.033 \pm 0.003$ & $0.004 \pm 0.00$ & $0.013 \pm 0.002$ & $0.003 \pm 0.00$ \\
$\boldsymbol{x t r C}$ (AN2358) & $0.15 \pm 0.01$ & $0.22 \pm 0.02$ & $0.17 \pm 0.02$ & $0.00 \pm 0.00$ & $0.14 \pm 0.02$ & $0.91 \pm 0.05$ & $0.28 \pm 0.02$ \\
$\boldsymbol{x t r D}$ (AN0250) & $3.95 \pm 0.00$ & $34.80 \pm 3.70$ & $9.48 \pm 2.24$ & $43.12 \pm 3.14$ & $15.09 \pm 0.03$ & $74.37 \pm 1.15$ & $31.12 \pm 3.46$ \\
$\boldsymbol{x t r E}$ (AN4148) & $0.18 \pm 0.01$ & $0.95 \pm 0.15$ & $1.08 \pm 0.24$ & $1.16 \pm 0.03$ & $0.77 \pm 0.00$ & $0.48 \pm 0.00$ & $0.45 \pm 0.00$ \\
\hline
\end{tabular}

Results are presented as mean \pm SD. 


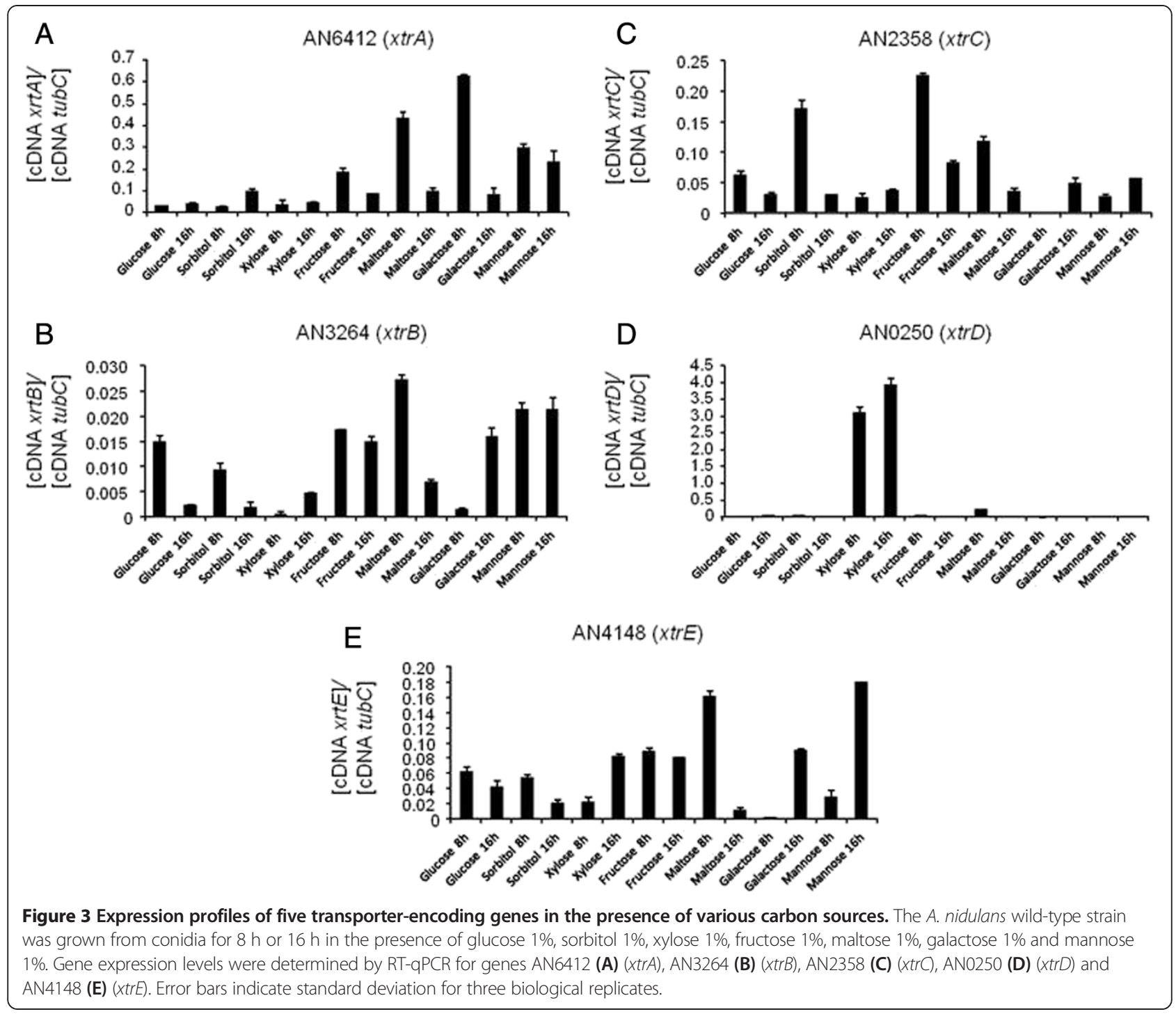

growth and conidiation patterns as the wild-type strain under all the tested conditions (data not shown). The growth of the same strains in liquid minimal medium supplemented with either $0.5 \%$ or $1.0 \%$ glucose, $0.5 \%$ or $1.0 \%$ xylose and $1.0 \%$ xylan was measured through determining fungal dry weight (Figure 6). There was no significant difference in biomass accumulation between the strains in any of the carbon sources (Figure 6). These results showed that the lack of a single transporter, $x \operatorname{tr} A-E$, did not result in a loss of growth in the presence of various carbon sources, suggesting gene redundancy.

\section{Characterization of the xtrD gene in S. cerevisiae}

$\mathrm{XtrD}$ was the only transporter specifically induced in the presence of xylose and was therefore selected for further study. Primarily, the correct localization of $\mathrm{XtrD}$ in $S$. cerevisiae was confirmed by cloning $x \operatorname{trD}$ fused to the $g f p$ gene into the centromeric modified vector pRH195, where the construct was under the control of the HXT7 promoter and terminator regions. Transformed into S. cerevisiae, XtrD::GFP was observed to be mainly targeted to the plasma membrane (Figure 7A), justifying the use of $S$. cerevisiae as a model.

The S. cerevisiae strain EBY.VW4000 lacks about 20 glucose transporters and is unable to grow on various monosaccharides, including glucose, fructose, mannose, galactose and xylose [21]. S. cerevisiae cannot efficiently utilize xylose as a sole carbon source. Therefore, to utilize the EBY.VW4000 as a tool for evaluating the capacity of $\mathrm{XtrD}$ to preferentially transport xylose, additional genes encoding enzymes for xylose utilization were introduced. Subsequently genes encoding proteins of the xylose utilization pathway were introduced into EBY.VW4000 via transformation with the $\mathrm{pRH} 274$ plasmid containing the $S$. stipitis XR and $\mathrm{XDH}$, plus the $S$. cerevisiae xylulose kinase $(X K S 1)$ genes (strain EBY + pRH274). These genes 


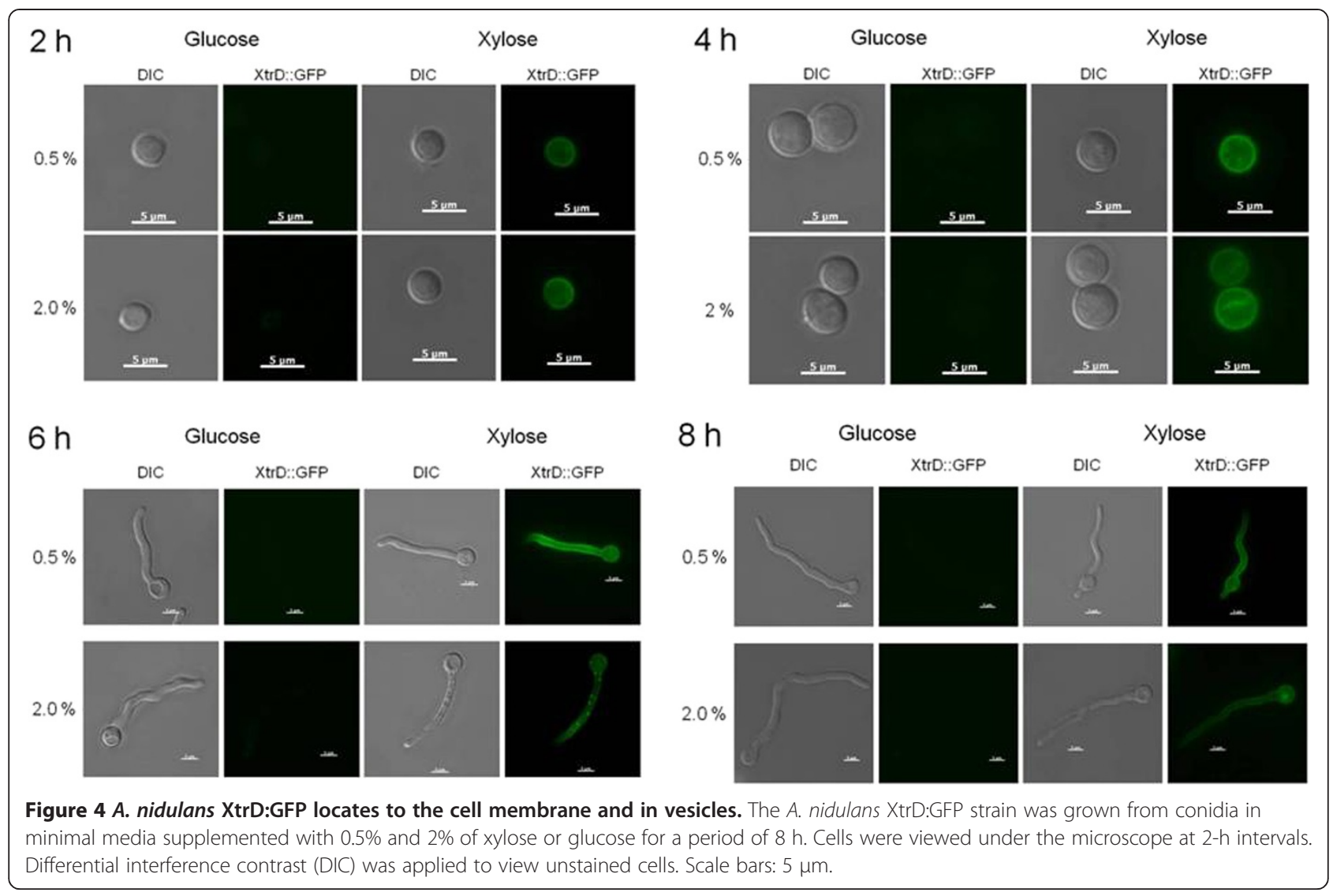

were put under the control of the PGK1, ADH1 and HXT7 constitutive promoters, respectively [9].

The EBY.VW4000 strain possessing the modified xylose utilization pathway was then transformed with pRH195m containing $x t r D$ under the control of the HXT7 constitutive promoter (strain EBY $+\mathrm{pRH} 274+\mathrm{pRH} 195 \mathrm{~m}$ ). The modified xylose utilization strain, with and without XtrD were grown in the presence of different monosaccharides. The respective strains were first grown in maltose-rich liquid medium before serial dilutions were prepared and both strains were transferred onto YNB agar plates containing one of the following carbon sources: maltose (control), glucose, xylose, galactose, fructose, mannose, sorbitol, sucrose and arabinose at a concentration of either $0.5 \%$ or $2.0 \%$. The drop-out assay showed that the expression of $\mathrm{XtrD}$ in the modified xylose utilization $\mathrm{EBY}+\mathrm{pRH} 274+\mathrm{pRH} 195 \mathrm{~m}$ strain was able to restore growth of this organism in the presence of glucose, indicating that $\mathrm{XtrD}$ was able to transport glucose (Figure 7B). In addition, the expression of XtrD restored the ability to grow on all other carbon sources tested, except for arabinose. This indicates that the transporter encoded by $x \operatorname{tr} D$ accepts multiple sugars as substrate. Interestingly, the expression of XtrD was only able to partially restore growth in the presence of xylose (Figure 7B).
The EBY + pRH274 + pRH195m strain expressing the components of the xylose utilization pathway and the $x \operatorname{tr} D$ gene were inoculated onto 10 plates containing minimal media supplemented with $2 \%$ xylose. After 21 days of incubation at $30^{\circ} \mathrm{C}$, around 40 colonies had grown on the plates. The colonies were then transferred onto new plates containing minimal medium supplemented with $2 \% \mathrm{xy}$ lose. Only four of the colonies (named hereafter clones 16, 22, 28 and 31) displayed consistent growth on xylose (data not shown). A drop-out assay of clone 28 showed improved growth on medium containing xylose, when compared to the growth of the parental $x t r D$-transformed strain, prior to the 3-week adaptation in xylose-rich media (Figure 7C; see also Additional file 2).

To check if any mutations had occurred in the $x \operatorname{trD}$ gene, plasmids were extracted from the four clones and the $x \operatorname{tr} D$ gene was sequenced. Sequencing results confirmed that in these strains no mutations had occurred in the $x \operatorname{trD}$ gene (data not shown). Furthermore, to verify that the observed enhanced growth of the clones was not due to any mutations in the genes encoding components of the xylose utilization pathway or in the $x t r D$ gene, both plasmids (one containing the three genes required for xylose utilization and one containing $x \operatorname{tr} D$ ) were extracted from all four strains and transformed back into the original EBY.VW4000 strain. Re-transformed 

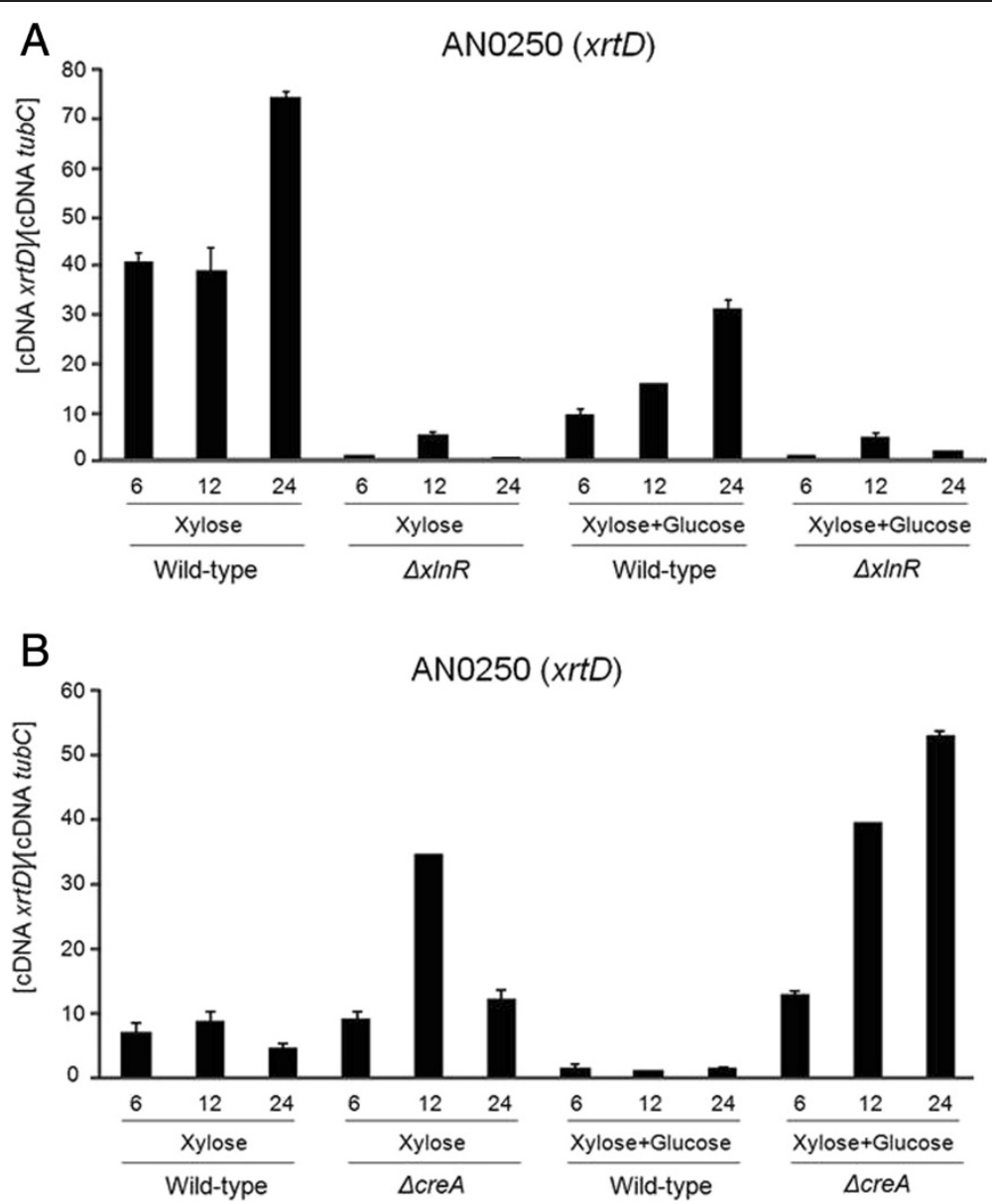

Figure 5 Transcriptional regulation of $A$. nidulans $x t r D$, in the presence of $x y l o s e$, is $X I n R$ and CreA-dependent. Transcript levels of $x t r D$ were determined by RT-qPCR in the $\Delta x \ln R(\mathbf{A})$ and $\Delta c r e A 4$ (B) strains with comparison to the wild-type strain (A and $\mathbf{B})$, grown for $6 \mathrm{~h}, 12 \mathrm{~h}$ and $24 \mathrm{~h}$ in the presence of xylose $(X)$ or xylose and glucose $(X+G)$. Error bars indicate the standard deviation for three replicates.

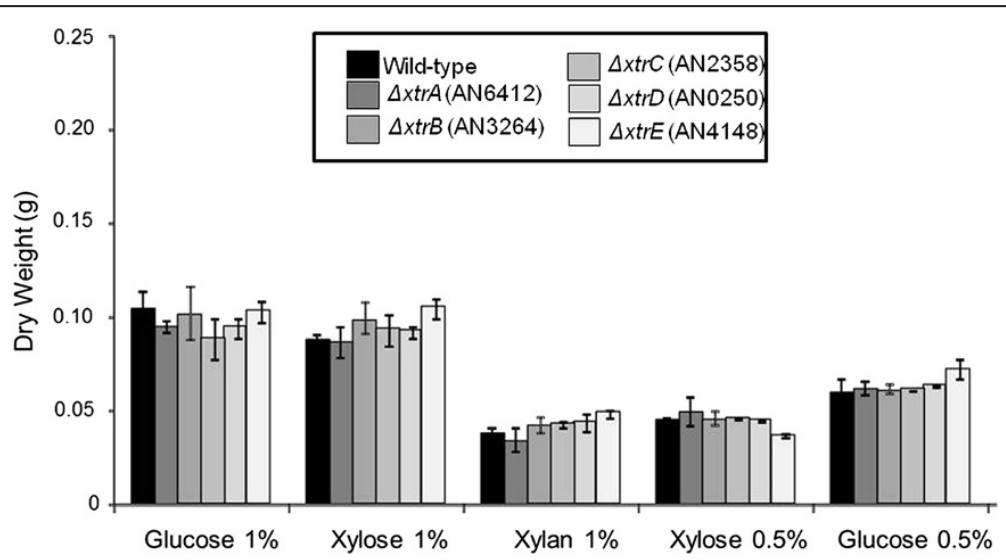

Figure 6 Growth of $A$. nidulans wild-type and $\triangle x t r A-E$ mutant strains in the presence of different carbon sources. Strains were grown from conidia in minimal media supplemented with the relevant carbon source (glucose $1.0 \%$, xylose $1.0 \%$, xylan $1.0 \%$, xylose $0.5 \%$ and glucose $0.5 \%$ ) at $37^{\circ} \mathrm{C}$ for $24 \mathrm{~h}$. Error bars indicate standard deviation for three biological replicates. 


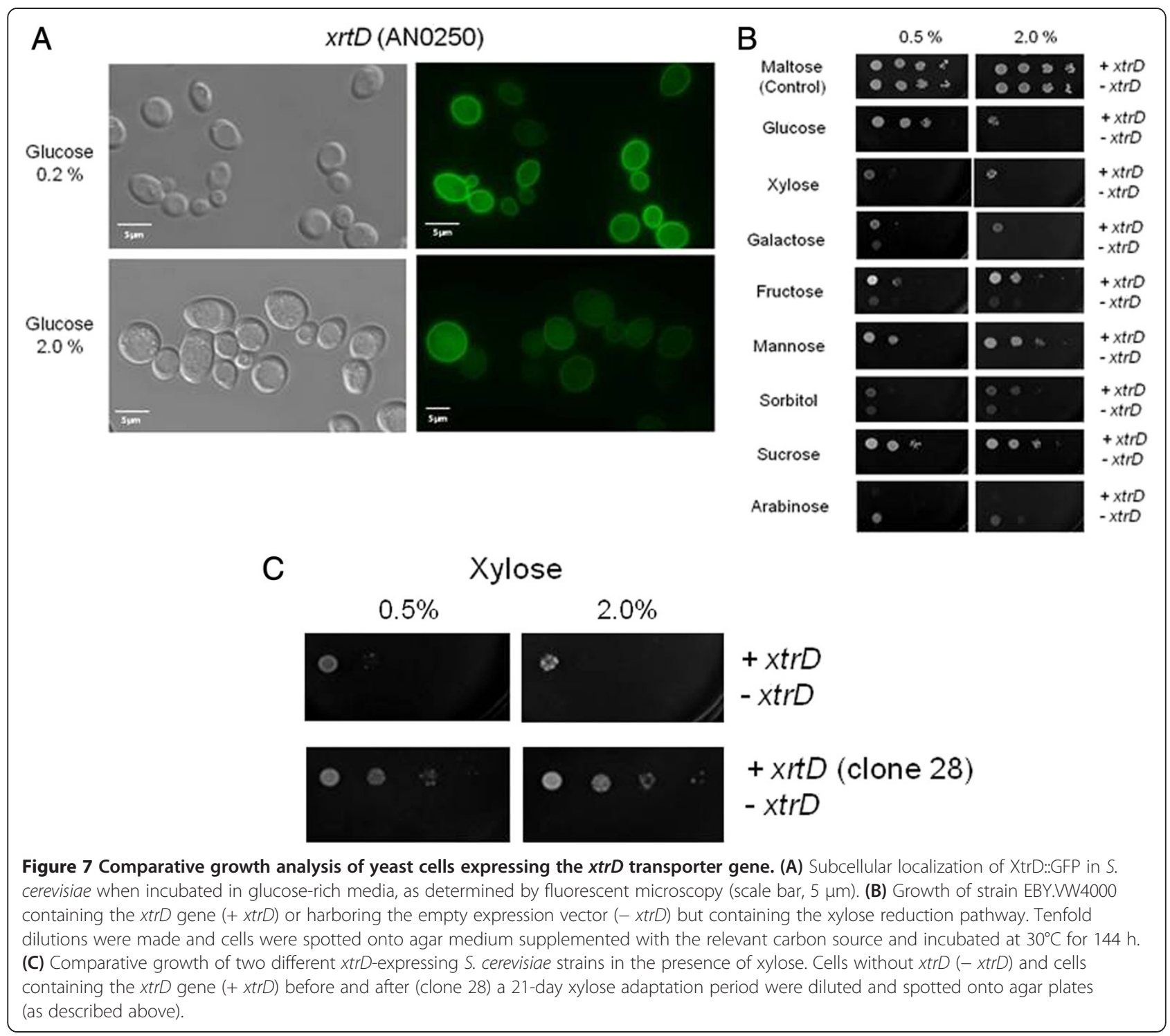

strains did not demonstrate enhance growth on xylose when compared to the respective clones, indicating that the acquired mutation(s) responsible for the adaptation to xylose did not reside on these two plasmids and must have had occurred elsewhere in the genome. In support of this hypothesis, both plasmids were cured from the four clones, resulting in a strain that could no longer utilize xylose. The cured clones were then retransformed first with pRH274 (containing the xylose utilization pathway genes) and subsequently with pRH195 (containing $x t r D$ ). Only clones harboring both plasmids were able to grow in the presence of $2 \%$ xylose (Additional file 3). These results suggest that we selected for mutation(s) in the EBY + pRH274 + pRH195m strain, beyond the four introduced genes, which enhanced the efficiency of this strain to sustain growth on $2 \%$ xylose.

\section{XtrD has high affinity for xylose}

The XtrD transporter was able to accept multiple sugars as substrates, such as glucose and xylose (Figure 7B). Considering that $\mathrm{XtrD}$ was able to transport glucose (Figure 7B), the original modified xylose utilization EBY. VW4000 strain expressing xtrD (non-adapted EBY + pRH274 + pRH195m strain) was grown in the presence of a constant concentration of glucose $(0.2 \%)$ and an increasing concentration of xylose (0.05 to $0.5 \%)$. Figures $8 \mathrm{~A}$ and $B$ showed that increasing concentrations of xylose dramatically decreased the growth of this strain. To confirm these physiological data, the uptake of $\left({ }^{14} \mathrm{C}\right)$ glucose in the absence or presence of increasing concentrations of xylose, as a potential transport competitor, was measured (Figure 8C). A 10- and 20-fold excess of unlabeled xylose inhibited the transport of radiolabeled glucose between $90 \%$ to $100 \%$, respectively (Figures $8 \mathrm{C}$ ). In addition, the 

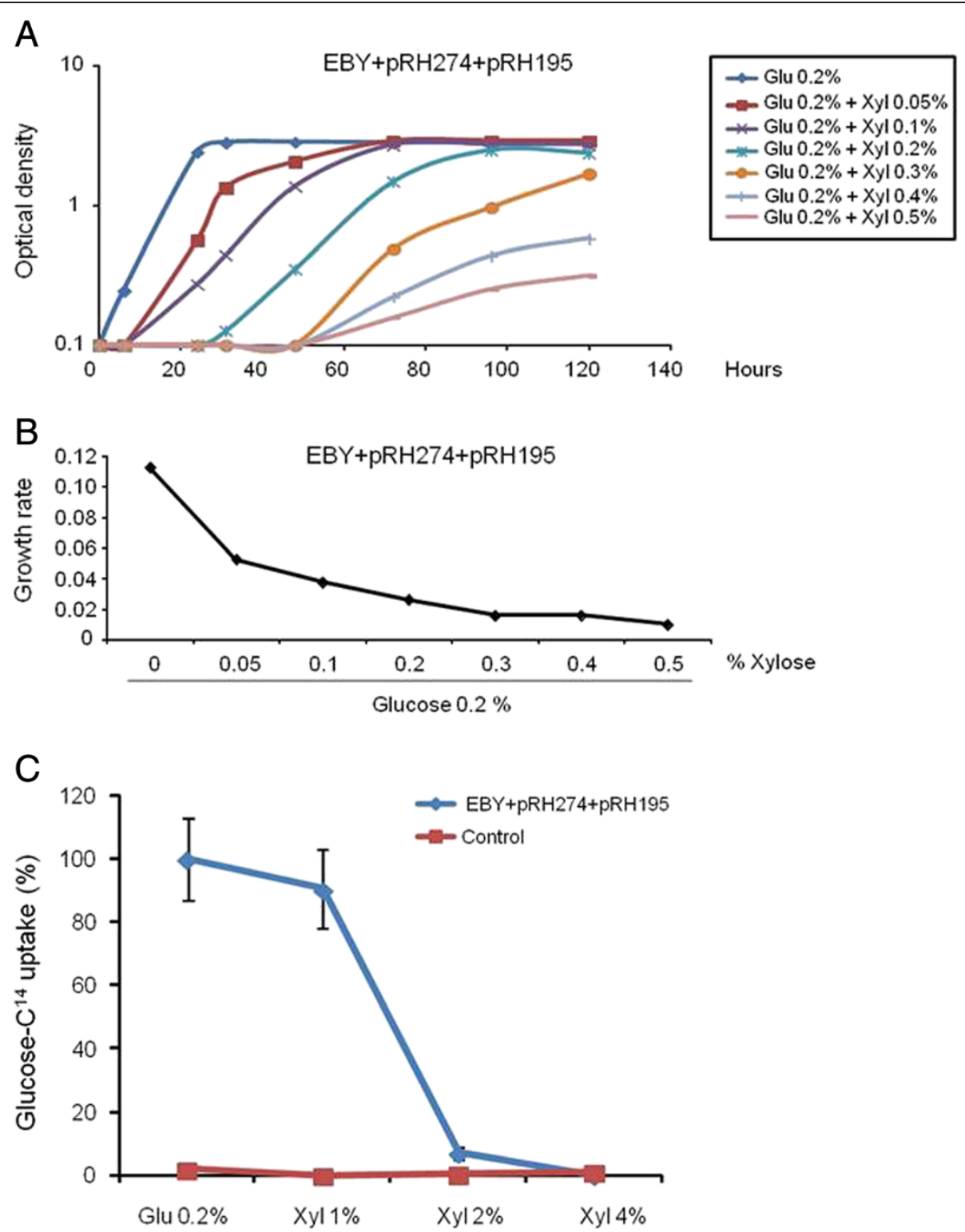

Figure 8 XtrD has higher affinity for xylose than glucose. (A) S. cerevisiae EBY.WW4000 containing the xrtD gene or harboring the empty expression vector were grown for $140 \mathrm{~h}$ at $30^{\circ} \mathrm{C}$ in YNB medium plus $0.2 \%$ glucose and increasing xylose concentrations. (B) Growth rate of the experiments are shown in (A). (C) Glucose and xylose substrate specificities of the XtrD transporter. Glucose and xylose specificities of XtrD were determined in yeast cells (strain EBY.WW4000) expressing the respective CDNA. Relative transport levels were determined in the absence of a competitor or in the presence of increasing concentrations of xylose ( $n=3, \pm$, standard deviation). The results are expressed as the percentage of inhibition of the transport with radiolabeled glucose.

expression of $x \operatorname{trD}$ in $A$. nidulans was higher when grown in the presence of lower concentration of xylose (Additional file 4, and Figure 4 and Figure 8D). These results suggest that XtrD has affinity for xylose, and may be a high-affinity xylose transporter.

\section{Discussion}

Economically viable $2 \mathrm{G}$ bioethanol production requires the development of efficient technologies for the cofermentation of the hexose and pentose sugars stored within plant biomass. The introduction of the xylose utilization pathway from other organisms into S. cerevisiae has proven insufficient [7] and xylose transport is proposed to be the limiting step. Filamentous fungi possess a greater capacity to consume pentose sugars $[17,18]$ and represent a possible source of genes for the engineering of pentose utilization in S. cerevisiae. Therefore, the aim of this study was to identify xylose transporters from $A$. nidulans, which may enhance xylose consumption in a modified $S$. cerevisiae strain, containing the xylose 
utilization pathway. Initially, the regulation of xylose utilization in A. nidulans was assessed to facilitate the identification of candidate xylose transporters. Xylose uptake was shown to be inhibited by glucose-induced CCR, whereas the carbon catabolite-derepressed strain, creAd30, consumed xylose even in the presence of glucose. In agreement, extracellular endoxylanase activity, which is induced by the presence of xylose or xylan, was suppressed by glucose-induced CCR. In contrast, the creAd30 strain demonstrated increased endoxylanase activity compared to the wild-type strain on xylose and xylose plus glucosecontaining media. This confirms that the CreA-mediated CCR inhibits the transcription of genes involved in the utilization of alternative carbon sources when glucose is detected [22,23]. Similar observations have been made in other filamentous fungi such as Trichoderma reesei, where glucose inhibits the uptake of the cellulase-inducer sophorose [24].

Genome-wide microarray analyses of $A$. nidulans post transfer to xylose-containing media enabled the identification of several highly upregulated transporter-encoding genes. Five such genes encoded transporters of the MFS. The MFS are single polypeptide secondary carriers that transport small soluble molecules in response to ion gradients [25]. The MFS comprises 17 families of which families 1 (SP - sugar porter family), 5 and 7 are specific for sugar transport [25]. The five candidate transporters demonstrated high sequence similarity (60\% to $80 \%$ identity at the protein level) to transporters from other fungi, highlighting the conservation of these proteins across species (data not shown). Furthermore, BLASTp analyses indicated that the five candidate transporters were likely to belong to MFS family 1 , which in S. cerevisiae and filamentous fungi includes members from the SP family that transport hexoses (for example, glucose, galactose), pentoses (for example, xylose), disaccharides (for example, lactose), quinate and inositols [25]. Due to the lack of information concerning the characterization of fungal transporters, it was not possible to predict the primary functions of the five candidate transporters, based on homology to other known transporters. This underlines the importance to conduct detailed investigation into fungal transporters.

Expression profiles of the five transporter-encoding genes were then further characterized in the presence of various monosaccharides including xylose. Only one gene (ID AN0250), named hereafter $x \operatorname{trD}$ (xylose transporter), was specifically induced in the presence of xylose. This gene and its homologues have already previously been shown to be highly expressed in the presence of xylose in A. nidulans, A. niger and A. oryzae [26]. Furthermore, the $x t r D$ homologue in $T$. reesei (ID 50893), was shown to be highly upregulated when transferring the fungus from glucose to a complex lignocellulosic carbon source [27].
Fusion of XtrD with GFP further confirmed the expression of $x \operatorname{tr} D$ and the location of the corresponding protein to the cell membrane and to vesicles during the first $8 \mathrm{~h}$ of incubation of fungal conidia in xylose-rich media.

The regulation of $x \operatorname{tr} D$ in the presence of repressing and inducing carbon sources was characterized. The induction of $x \operatorname{tr} D$ was shown to be XlnR-dependent, whereas $x \operatorname{tr} D$ repression was CreA-dependent, as suggested by the previous phenotypic assays for xylose utilization and endoxylanase activity. Indeed, Andersen et al. [26] identified an XlnR binding motif ( $5^{\prime}$-GGNTAAA-3') in the promoter region of $x \operatorname{tr} D$ in $A$. nidulans, $A$. niger and $A$. oryzae. In Aspergilli, $\mathrm{X} \ln \mathrm{R}$ is involved in the induction of xylanases, $\beta$-xylosidases, cellobiohydrolases, endoglucanases, galactosidases, arabinofuranosidases and carbohydrate esterases in the presence of the inducer D-xylose [28]. In the presence of glucose, the same hydrolases, esterases and transporters are repressed by the CCR, CreA. This allows the fungus to select the most energetically favorable carbon source and not waste energy on the secretion of polysaccharide-degrading enzymes [22,23]. Both transcription factors, XlnR and CreA, therefore, coordinate the regulation of genes encoding proteins required for carbon source metabolism and acquisition, including transporters.

The genome of $A$. nidulans contains over 30 genes encoding transporters of the MFS (www.aspgd.org), suggesting the existence of functional redundancy among transporters. Single-gene disruption studies of the five candidate xylose transporter-encoding genes had no significant impact on fungal growth on different carbon sources including xylose, probably due to redundancy. An alternative strategy was required to assess gene function. Subsequently, the most promising candidate, $x \operatorname{trD}$, was cloned into the $S$. cerevisiae strain EBY. VW4000 that lacks all hexose transporters, harbors the components of the xylose reductive pathway, but is unable to grow on a range of sugars including glucose and xylose. The correct sub-cellular localization of XtrD:: GFP to the plasma membrane was confirmed. The introduction of $x \operatorname{trD}$ restored the ability to grow on glucose, fructose, mannose, sorbitol and sucrose. Therefore, $\mathrm{XtrD}$ can transport multiple sugars, which is not surprising as many fungal transporters exhibit a wide range of substrate binding [11]. This is advantageous when fungi encounter complex lignocellulosic material, which contains multiple hexose and pentose sugars. However, the recovery of growth on xylose was limited, indicating that $\mathrm{XtrD}$ and components of the xylose utilization pathway are not enough to fully restore growth on this pentose sugar. Interestingly, when expressed in S. cerevisiae, XtrD showed a high affinity for xylose, even allowing the growth inhibition of $S$. cerevisiae in the presence of glucose. 
To further enhance xylose utilization, the $x \operatorname{tr} D$-containing, transformed strain was incubated for three weeks on xylose-rich media, resulting in cells that exhibited much improved growth on xylose via adaptive evolution. Attempts made to identify the cause of this improvement, revealed that this strain required both plasmids (harboring the xylose utilization genes and transporter-encoding gene) for growth on xylose, but these plasmids alone did not confer the enhanced ability to grow on xylose. Therefore, the mutation(s) that occurred within the S. cerevisiae genome had a synergistic effect, along with $x \operatorname{tr} D$ and the xylose reduction pathway, on xylose utilization. A similar investigation by Saloheimo et al. [29], where S. cerevisiae was transformed with the T. reesei gene xlt1 (ID 104072), produced similar results and conclusions. Adaptive evolution is a powerful tool for improving the growth of yeast strains in different carbon sources, but pinning down the resulting mutations responsible for the observed phenotype requires whole genome sequencing and subsequent genetic mutation studies, which is labor-intensive and costly. An alternative method to adaptive evolution in yeast could be targeted protein engineering. Young et al. [30] used directed evolution in yeast to create mutations in several transporters. They managed to engineer transporters with improved xylose-transporting capacity and although challenges remain such as the tradeoff between transport efficiency and substrate affinity, or the preference of glucose to xylose, protein engineering seems to be a promising tool to create ideal xylose transporters for lignocellulose biomass conversion.

\section{Conclusion}

Efficient pentose uptake and the subsequent fermentation remains a bottleneck in $2 \mathrm{G}$ bioethanol production. Screening of the genomes of filamentous fungi (for example, $A$. nidulans, $T$. reesei) has resulted in the identification of promising xylose transporters, but these proteins probably need to be fine-tuned in order to improve their efficiency and capacity for pentose uptake and to de-select for the preference towards glucose. This study characterized the regulation and substrate specificity of a transporter that represents a good candidate for further directed mutagenesis. Investigation into the area of sugar transport (characterization of transporters from the MFS and directed mutagenesis of transporters) in fungi presents a crucial step for improving the conversion of lignocellulosic biomass into bioethanol. Nonetheless, the localization of the adaptive mutations beyond the introduced xylose utilization genes demonstrates the complexity of the system that involves many additional genes, providing substantial room for significant biotechnological improvements in xylose utilization efficiencies.

\section{Methods}

\section{Strains, media and culture methods}

The A. nidulans and $S$. cerevisiae strains used in this study are described in Table 5 . All $A$. nidulans strains were grown in minimal media $(1 \%(\mathrm{w} / \mathrm{v})$ glucose, $50 \mathrm{ml}$ of a $20 \times$ salt solution $\left(120 \mathrm{~g} / \mathrm{NaNO}_{3}, 10.4 \mathrm{~g} / \mathrm{l} \mathrm{KCl}\right.$, $\left.30 \mathrm{~g} / \mathrm{l} \mathrm{KH}_{2} \mathrm{PO}_{4}, 10.4 \mathrm{~g} / \mathrm{l} \mathrm{MgSO}_{4}\right), 1 \mathrm{ml}$ of $5 \times$ trace elements $\left(22.0 \mathrm{~g} / \mathrm{l} \mathrm{ZnSO} 4,11 \mathrm{~g} / \mathrm{l}\right.$ boric acid, $5 \mathrm{~g} / \mathrm{l} \mathrm{MnCl}_{2}, 5 \mathrm{~g} /$ $1 \mathrm{FeSO}_{4}, 1.6 \mathrm{~g} / \mathrm{CoCl}_{2}, 1.6 \mathrm{~g} / \mathrm{l} \mathrm{CuSO}_{4}, 1.1 \mathrm{~g} / \mathrm{l}\left(\mathrm{NH}_{4}\right)$ ${ }_{2} \mathrm{MoO}_{4}, 50 \mathrm{~g} / \mathrm{l}$ ethylenediaminetetraacetic acid (EDTA)) and adjusted to $\mathrm{pH} 6.5$ with $\mathrm{NaOH}$. S. cerevisiae was grown in a solution containing $7 \mathrm{~g} / \mathrm{l}$ Yeast Nitrogen Base without amino acids, histidine $(0.1 \mathrm{~g} / \mathrm{l})$, lysine $(0.1 \mathrm{~g} / \mathrm{l})$, leucine $(0.1 \mathrm{~g} / \mathrm{l})$, tryptophan $(0.1 \mathrm{~g} / \mathrm{l})$, uridine $(1.2 \mathrm{~g} / \mathrm{l})$ and uracil $(1.2 \mathrm{~g} / \mathrm{l})$. All reagents were obtained from Sigma Aldrich (St. Louis, MO, USA), except where stated.

\section{Endoxylanase activity}

Endoxylanase (endo-1,4- $\beta$-xylanase) activity was measured, using Azo-Xylan from Birchwood (Megazyme International, Bray, Ireland) as a substrate. The enzyme assay was carried out according to the manufacturer's (Megazyme) instructions. Briefly, $500 \mu \mathrm{l}$ of the sample supernatant (containing the xylanases) was mixed with $500 \mu \mathrm{l}$ of $100 \mathrm{mM}$ sodium acetate buffer ( $\mathrm{pH} 4.5$ ). Then, $500 \mu \mathrm{l}$ of the diluted enzyme preparation was mixed with $500 \mu \mathrm{l}$ substrate solution ( $1 \% \mathrm{w} / \mathrm{v}$ Azo-Xylan). The samples were incubated at $40^{\circ} \mathrm{C}$ for 10 minutes and then the reactions were stopped via the addition of $2.5 \mathrm{ml}$ ethanol $(95 \% \mathrm{v} / \mathrm{v})$. Samples were centrifuged for $10 \mathrm{mi}$ nutes at $1,000 \times g$. The supernatant was removed and absorbance was measured at $590 \mathrm{~nm}$. Enzymatic activity was determined using the Mega-Calc ${ }^{\mathrm{TM}}$ software (Megazyme International). One unit of enzymatic activity was defined as the amount of enzyme required to release $1 \mathrm{mM}$ of D-xylose from arabinoxylan per minute $(\mathrm{pH} 4.5)$ at $40^{\circ} \mathrm{C}$.

\section{Xylose and glucose uptake}

A. nidulans strains were grown in $50 \mathrm{ml}$ minimal media supplemented with $1 \%(\mathrm{w} / \mathrm{v})$ glucose or $1 \%(\mathrm{w} / \mathrm{v})$ xylose at $37^{\circ} \mathrm{C}, 150 \mathrm{rpm}$, for different time periods. At each time point, $5.0 \mathrm{ml}$ of the culture supernatant was harvested. Glucose and xylose concentrations of the supernatants were measured using the Glucose GOD-PAP Liquid Stable Mono-reagent enzymatic kit from LaborLab Laboratories Ltd. (Guarulhos, SP, Brazil) and the D-xylose assay kit from Megazyme. All assays were carried out according to manufacturer's instructions.

\section{Molecular techniques}

Standard $A$. nidulans strain construction and transformation techniques were used throughout this study [36]. All DNA manipulations were performed as previously described [37]. Deletion cassettes were provided by the Fungal 
Table 5 A. nidulans and S. cerevisiae strains used in this work

\begin{tabular}{|c|c|c|}
\hline Strain & Genotype & References \\
\hline \multicolumn{3}{|l|}{ A. nidulans } \\
\hline TNO2a3 & pyrG89;pyroA4; $\Delta n k u 70:: a r g B$ & Reference [31] \\
\hline R21 & yA1 pabaA1 & Reference [32] \\
\hline$\Delta x \ln R$ & pabaA1;FwA1;uaY9;pyrG89; $\Delta x \ln R::$ pyr4 & Reference [33] \\
\hline$\Delta c r e A 4$ & pantoB100;cre $\Delta 4 ;$;ua211 & Reference [34] \\
\hline creAd30 & creA30; biAl; wA3 & Reference [35] \\
\hline$\Delta$ AN0250 & pyrG89; pyroA4; $\Delta n k u 70:: a r g B \Delta x t r D:: p y r G$ & This work \\
\hline$\Delta$ AN6412 & pyrG89; pyroA4; $\triangle n k u 70:: a r g B ; \Delta x t r A:: p y r G$ & This work \\
\hline$\Delta$ AN3264 & pyrG89; pyroA4; $\Delta n k u 70:: a r g B ; \Delta x t r B:: p y r G$ & This work \\
\hline$\Delta$ AN2358 & pyrG89; pyroA4; $\Delta n k u 70:: a r g B ; \Delta x t r C:: p y r G$ & This work \\
\hline$\triangle \mathrm{AN} 4148$ & pyrG89; pyroA4; $\Delta n k u 70:: \operatorname{argB;}$ xtrE::pyrG & This work \\
\hline XtrD::GFP & pyrG89; pyroA4; $\triangle n k u 70:: \operatorname{argB;}$ XtrD::GFP::pyrG & This work \\
\hline \multicolumn{3}{|l|}{ S. cerevisiae } \\
\hline EBYWW4000 & 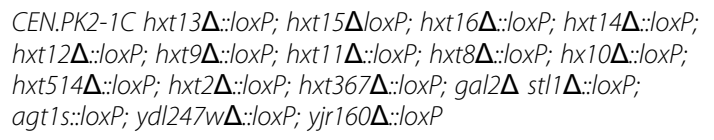 & Reference [21] \\
\hline $\mathrm{EBI}+\mathrm{XrtD}:: \mathrm{GFP}$ & EBYW4000 pRH195 XtrD::GFP & This work \\
\hline $\mathrm{EBI}+\mathrm{pRH} 274+\mathrm{pRH} 195 \mathrm{~m}$ & EBYW4000 pRH195 xtrD pRH274 & This work \\
\hline $\mathrm{EBI}+\mathrm{pRH} 195$ & EBYW4000 pRH195 & This work \\
\hline $\mathrm{EBI}+\mathrm{pRH} 274+\mathrm{pRH} 195$ & EBYW4000 pRH195 pRH274 & This work \\
\hline Clone 16 & EBYWW4000 pRH195m pRH274 mutated & This work \\
\hline Clone 22 & EBYWW4000 pRH195m pRH274 mutated & This work \\
\hline Clone 28 & EBYWW4000 pRH195m pRH274 mutated & This work \\
\hline Clone 31 & EBYWW4000 pRH195m pRH274 mutated & This work \\
\hline
\end{tabular}

Genetics Stock Centre (FGSC) (www.fgsc.net). PCR reactions were performed using the TaKaRa Ex Taq DNA Polymerase (Takara BIO Inc., Shiga, Japan), according to manufacturer's instructions. Primer-pair details are described in Additional file 5. Transformed strains were grown on minimal medium depleted in uridine and uracil and checked for the presence of the correct insertion by PCR.

\section{Cloning of heterologous genes}

Gene fragments were amplified by PCR, using Phusion DNA polymerase (Thermo Fisher Scientific, Waltham, MA, USA) according to manufacturer's protocols. PCR primers used for all gene amplifications and plasmids are listed in Additional files 5 and 6. Plasmid pRH195 was linearized using restriction enzymes SalI and SpeI [New England Biolabs (NEB), Ipswich, MA, USA) and yeast were transformed with plasmid pRH195 and the appropriate DNA fragments according to the previously described protocol [38].

\section{Yeast growth rates}

The growth rates of the transformed yeast strains when grown in SC-URA for $24 \mathrm{~h}$ at $30^{\circ} \mathrm{C}, 150 \mathrm{rpm}$, were performed in triplicate and recorded via measuring the optical density (OD) of the cultures at $640 \mathrm{~nm}$. Subsequently, these cells were transferred to $100 \mathrm{ml}$ YNB media supplemented with the respective carbon source at $30^{\circ} \mathrm{C}$, $150 \mathrm{rpm}$, at a starting $\mathrm{OD}_{640}$ of 0.1 .

\section{A. nidulans growth rates}

A. nidulans strains were cultivated (from $10^{6}$ conidia) in $25 \mathrm{ml}$ minimal media supplemented with the respective carbon source at $37^{\circ} \mathrm{C}, 150 \mathrm{rpm}$, for different periods of time. At each time point, mycelia were harvested, snapfrozen in liquid nitrogen and freeze-dried, before the dry weight was recorded.

\section{Staining and microscopy}

Conidia of the $A$. nidulans $x \operatorname{trD}:: G F P$ strain were inoculated onto coverslips mounted within $5 \mathrm{ml}$ of minimal media supplemented with the respective carbon source, for the specified conditions (see Results). Germinating conidia were then fixed (3.7\% formaldehyde, $50 \mathrm{~mm}$ sodium phosphate buffer $\mathrm{pH} 7.0,0.2 \%$ Triton $\mathrm{X}-100$ ) for 30 minutes at room temperature. Coverslips were then rinsed with PBS buffer $(140 \mathrm{mM} \mathrm{NaCl}, 2 \mathrm{mM} \mathrm{KCl}$, 
$10 \mathrm{mM} \mathrm{NaHPO}, 1.8 \mathrm{mM} \mathrm{KH}_{2} \mathrm{PO}_{4}, \mathrm{pH}$ 7.4) and incubated for 5 minutes at room temperature in a solution containing $100 \mathrm{ng} / \mathrm{ml}$ 4',6-diamidino-2-phenylindole (DAPI; Sigma Chemical, St. Louis, MO, USA). Coverslips were again washed with PBS buffer at room temperature and examined under the microscope.

Mycelia were viewed under a Carl Zeiss (Jena, Germany) AxioObserver.Z1 fluorescent microscope equipped with a $100-$ W HBO mercury lamp, using the $100 \times$ magnification oil immersion objective (EC Plan-Neofluar, NA 1.3). Phase-contrast brightfield and fluorescent images were taken with an AxioCam camera (Carl Zeiss) and processed using AxioVision software (version 3.1). Images were exported and further processed using Adobe Photoshop 7.0 (Adobe Systems Incorporated, San Jose, CA, USA).

RNA extraction, cDNA synthesis and real-time PCR reactions To quantify gene expression levels in the presence of different carbon sources, a total of $10^{7} \mathrm{~A}$. nidulans conidia were inoculated in minimal media supplemented with the respective carbon source for $8 \mathrm{~h}$ or $16 \mathrm{~h}$ at $37^{\circ} \mathrm{C}, 150 \mathrm{rpm}$. Mycelia were harvested and snap-frozen in liquid nitrogen. For media transfer experiments, cultures grown in the presence of fructose (control) were inoculated with $10^{7}$ wild-type $A$. nidulans conidia were inoculated in minimal medium supplemented with $25 \mathrm{mM}$ fructose for $16 \mathrm{~h}$ at $37^{\circ} \mathrm{C}, 150 \mathrm{rpm}$. Mycelia were then washed three times with sterile water and transferred into minimal medium containing $1 \%$ xylose or $1 \%$ xylose plus $1 \%$ glucose, for $6 \mathrm{~h}, 12 \mathrm{~h}$ and $24 \mathrm{~h}$. All mycelia were harvested and snapfrozen in liquid nitrogen.

Mycelia were then ground into a fine powder under liquid nitrogen and RNA was extracted using Trizol (Invitrogen, Carlsbad, CA, USA), according to manufacturer's instructions. The quality of the RNA $(10 \mu \mathrm{g})$ was checked on a $1.2 \%$ agarose gel containing $2.2 \mathrm{M}$ formaldehyde. RNA samples were DNAse-treated as previously described [39], purified with the RNeasy ${ }^{\oplus}$ Mini Kit (Qiagen, Valencia, CA, USA) and quantified using the NanoDrop 2000 Thermo Scientific (Uniscience, São Paulo, SP, Brazil) machine.

The cDNA was synthesized from $20 \mu \mathrm{g}$ RNA (Superscript II kit, Invitrogen), according to manufacturer's instructions. All RT-qPCR reactions were performed using the ABI 7500 Fast Real-Time PCR System (Applied Biosystems, Foster City, CA, USA) and the SYBR Green PCR Master Mix kit (Applied Biosystems), according to manufacturer's instructions. Reactions and calculations were performed as previously described [39]. Primer pairs are listed in Additional file 5.

Microarray slides construction and gene expression methods Microarray slides were designed exactly as described previously [40]. Samples were labeled with Cy-3 or Cy-5dUTP using the two-color microarray-based gene expression analysis kit (Quick Amp Labeling Kit, Agilent Technologies $^{\mathrm{TM}}$, Santa Clara, CA, USA), according to the manufacturer's instructions. Amplification and labeling of cRNA were performed through the addition of the Agilent $^{\mathrm{TM}}$ Transcription Master Mix $(20 \mu \mathrm{l}$ 4X Transcription Buffer, $6 \mu \mathrm{l} 0.1$ M DTT, $8 \mu \mathrm{l}$ NTP mix, $6.4 \mu \mathrm{l}$ 50\% PEG, $0.5 \mu \mathrm{l}$ RNase OUT, $0.6 \mu \mathrm{l}$ inorganic pyrophosphatase, $0.8 \mu \mathrm{l}$ T7 RNA Polymerase, $2.4 \mu \mathrm{l}$ Cyanine 3-CTP for the control samples, or cyanine 5-CTP for the treated samples, and $15.3 \mu \mathrm{l}$ nuclease-free water). Samples were then incubated at $40^{\circ} \mathrm{C}$ for $2 \mathrm{~h}$. The labeled cRNA was purified using the RNeasy ${ }^{\circ}$ Mini Kit (Qiagen) and quantified on the NanoDrop 2000 Thermo Scientific (Uniscience).

To prepare samples for hybridization, $825 \mathrm{ng}$ of each labeled cRNA was mixed with Agilent ${ }^{\mathrm{TM}}$ (Agilent $^{\mathrm{TM}}$ Technologies) Fragmentation Mix (11 $\mu$ l 10X blocking agent, $2.2 \mu \mathrm{l} 25 \mathrm{X}$ fragmentation buffer, and nuclease-free water to bring the volume to $52.8 \mu \mathrm{l}$ ) and incubated at $60^{\circ} \mathrm{C}$ for 30 minutes. The fragmentation reactions were stopped through the addition of $55 \mu \mathrm{l}$ of $2 \mathrm{X}$ GE Hybridization Buffer HI-RPM. For microarray hybridizations, $100 \mu \mathrm{l}$ of the sample was added to the microarray slide, which was then mounted in an Agilent $^{\mathrm{Tm}}$ Microarray Hybridization Chamber, within an Agilent G2545A hybridization oven for $17 \mathrm{~h}$ at $65^{\circ} \mathrm{C}$. After hybridization, microarray slides were washed according to the manufacturer's instructions and scanned using the GenePix ${ }^{\odot}$ 4000B microarray scanner (Molecular Devices, Sunnyvale, CA, USA).

\section{Gene expression analysis}

The extraction of data from the TIFF files, generated through scanning the microarray slides, was performed using the Agilent Feature Extraction (FE) Software version 9.5.3.1 (Agilent Technologies). This software used the linear Lowess algorithm to subtract the background noise and obtain normalized intensity values. Normalized values were uploaded into the software Express Converter (version 2.1, TM4 platform available at http:// www.tm4.org/utilities.html), which converts the Agilent file format to the multi-experiment viewer (mev) file format that is compatible with the TM4 software used for microarray analysis (available at http://www.tm4.org/). The mev files were uploaded into the MIDAS software (TM4 platform), where averages for each gene-replicate, from the biological replicates, were generated. Finally, analysis of the mev files was carried out using the TIGR MeV (TM4 platform, Multi Experiment Viewer, available at http://www.tigr.org/software/microarray.shtml) software. Differentially expressed genes were defined as those that had a mean $\log _{2}$ expression ratio statistically different from 0 , identified through applying the oneclass $t$-test $(P>0.01)$. 


\section{Competition assays}

For competition assays using S. cerevisiae strains, $500 \mathrm{ml}$ of SC-Trp medium supplemented with $0.2 \%$ glucose $(11 \mathrm{mM})$ were inoculated with the EBY.WV4000 strain harboring the $x \operatorname{tr} D$ gene. Cultures started with an initial $\mathrm{OD}_{640}$ of 0.1 and were grown until they reach $\mathrm{OD}_{640}$ of approximately 0.6 . Cells were harvested by centrifugation $(4,000 \mathrm{rpm})$, washed twice with $50 \mathrm{ml}$ ice-cold water and re-suspended in $1,250 \mu \mathrm{l}$ of water. A total of $400 \mu \mathrm{l}$ of these cells was diluted in $800 \mu \mathrm{l}$ of water and $40-\mu \mathrm{l}$ aliquots were transferred to $15 \mathrm{ml}$ falcon tubes which were then incubated at $30^{\circ} \mathrm{C}$ for 5 minutes for temperature equilibration. For competition experiments, $10 \mu \mathrm{l}$ of water containing different concentrations of xylose (competitor carbon source) plus $0.2 \mu \mathrm{Ci}$ of ${ }^{14} \mathrm{C}$-glucose were added. Sugar uptake was allowed for 5 seconds through vigorous vortexing. The reaction was then immediately stopped by quenching with $1.5 \mathrm{ml}$ ice-cold water and filtration over nitrocellulose filters (Fisher Scientific, Waltham, MA, USA) mounted in a vacuum manifold, followed by two consecutive washes with $1.5 \mathrm{~mL}$ of ice-cold water. Filters were then transferred to $8 \mathrm{ml}$ of ScintiSafeTM Econo1 scintillation liquid (Fisher Scientific). The D-(U-14C) glucose taken up by cells was measured using the Tri-Carb ${ }^{\circ}$ 2100TR Liquid Scintillation Counter (Perkin Elmer, Waltham, MA, USA).

\section{Additional files}

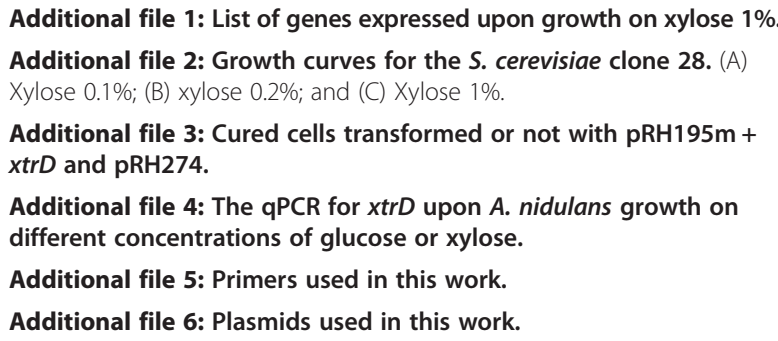

\section{Abbreviations}

1G: first-generation technologies; 2G: second generation technologies; CCR: carbon catabolite repression; mev: multi-experiment viewer; MFS: major facilitator superfamily; NAD: nicotinamide adenine dinucleotide;

$\mathrm{NADH}$ : reduced nicotinamide-adenine dinucleotide; NADPH: Nicotinamide adenine dinucleotide phosphate; OD: optical density; PBS: phosphatebuffered saline; $\mathrm{XDH}$ : xylitol dehydrogenase; XKS1: S. cerevisiae xylulose kinase; $X R$ : xylose reductase.

\section{Competing interests}

The authors declare that they have no competing interests.

\section{Authors' contributions}

LNAR, NAB, TFR, MHS, and FR: conception and design, data collection and analysis, manuscript writing and final approval of the manuscript. ACC, MS and JFM: data collection and analysis, critical revision and final approval of the manuscript. GHG: conception and design, financial support, manuscript writing, final approval of manuscript. All authors read and approved the final manuscript.

\section{Acknowledgements}

We would like to thank the Conselho Nacional de Desenvolvimento Científico e Tecnológico (CNPq) and the Fundação de Amparo à Pesquisa do Estado de São Paulo (FAPESP) for providing financial support. We also thank Dr Eckardt Boles for providing the EBY.WW4000 yeast strain, Dr Ronald Hector for providing the plasmids $\mathrm{pRH} 274$ and $\mathrm{pRH} 195$, Dr Michel Flipphi for providing the $\Delta c r e A 4$ strain, and the two anonymous reviewers for their comments and suggestions. We also acknowledge the Program project grant GM068087 (PI Jay Dunlap) for providing the deletion cassettes.

\section{Author details}

${ }^{1}$ Departamento de Ciências Farmacêuticas, Faculdade de Ciências Farmacêuticas de Ribeirão Preto, Universidade de São Paulo, Av. do Café S/N, CEP 14040-903 Ribeirão Preto, São Paulo, Brazil. 'Faculdade de Filosofia, Ciências e Letras de Ribeirão Preto, Universidade de São Paulo, São Paulo, Brazil. ${ }^{3}$ ICVS/3B's - PT Government Associate Laboratory, Braga/Guimarães, Portugal and Life and Health Sciences Research Institute (ICVS), School of Health Sciences, University of Minho, Braga, Portugal. ${ }^{4}$ Laboratório Nacional de Ciência e Tecnologia do Bioetanol - CTBE, Caixa Postal 617013083-970 Campinas, São Paulo, Brazil.

Received: 26 December 2013 Accepted: 13 March 2014 Published: 1 April 2014

\section{References}

1. Amorim HV, Lopes ML, de Castro Oliveira JV, Buckeridge MS, Goldman GH: Scientific challenges of bioethanol production in Brazil. Appl Microbiol Biotechnol 2011, 91:1267-1275.

2. Della-Bianca BE, Basso TO, Stambuk BU, Basso LC, Gombert AK: What do we know about the yeast strains from the Brazilian fuel ethanol industry? Appl Microbiol Biotechnol 2013, 97:979-991.

3. Himmel ME, Ding S-Y, Johnson DK, Adney WS, Nimlos MR, Brady JW, Foust TD: Biomass Recalcitrance: engineering plants and enzymes for biofuels production. Science 2007, 315:804-807.

4. Jeewon L: Biological conversion of lignocellulosic biomass to ethanol. J Biotechnol 1997, 56:1-24.

5. Jordan DB, Bowman MJ, Braker JD, Dien BS, Hector RE, Lee CC, Mertens JA, Wagschal K: Plant cell walls to ethanol. Biochem J 2012, 442:241-252.

6. Matsushika A, Inoue H, Kodaki T, Sawayama S: Ethanol production from xylose engineered Saccharomyces cerevisiae strains: current state and perspectives. Appl Microbiol Biotechnol 2009, 84:37-53.

7. Kim SR, Ha SJ, Wei N, Oh EJ, Jin YS: Simultaneous co-fermentation of mixed sugars: a promising strategy for producing cellulosic ethanol. Trends Biotechnol 2012, 30:274-282.

8. Ha SJ, Galazka JM, Kim SR, Choi JH, Yang X, Seo JH, Glass NL, Cate JH, Jin YS Engineered Saccharomyces cerevisiae capable of simultaneous cellobiose and xylose fermentation. Proc Natl Acad Sci U S A 2011, 108:504-509.

9. Hector RE, Mertens JA, Bowman MJ, Nichols NN, Cotta MA, Hughes SR: Saccharomyces cerevisiae engineered for xylose metabolism requires gluconeogenesis and the oxidative branch of the pentose phosphate pathway for aerobic xylose assimilation. Yeast 2011, 28:645-660.

10. Young $E$, Lee S-M, Alper H: Optimising pentose utilization in yeast: the need for novel tools and approaches. Biotechnol Biofuels 2010, 3:24.

11. Young E, Poucher A, Comer A, Bailey A, Alper H: Functional survey for heterologous sugar transport proteins using Saccharomyces cerevisiae as a host. Appl Environ Microbiol 2011, 77:3311-3319.

12. Gong CS, Chen LF, Flickinger MC, Chiang LC, Tsao GT: Production of ethanol from $D$-xylose by using $D$-xylose isomerase and yeasts. Appl Environ Microbiol 1981, 41:430-436.

13. Ho NW, Chen Z, Brainard AP: Genetically engineered Saccharomyces yeast capable of effective cofermentation of glucose and xylose. Appl Environ Microbiol 1998, 64:1852-1859.

14. Hahn-Hägerdal B, Karhumaa K, Jeppsson M, Gorwa-Grauslund MF: Metabolic engineering for pentose utilization in Saccharomyces cerevisiae. Adv Biochem Eng Biotechnol 2007, 108:147-177.

15. Chiang LC, Hsiao HY, Veng PP, Chen LF, Tsao GT: Ethanol production from xylose by enzymatic isomerization and yeast fermentation. Biol Bioeng Symp 1981, 11:263-274.

16. Gárdonyi M, Jeppsson M, Lidén G, Gorwa-Grauslund MF, Hahn-Hägerdal B: Control of xylose consumption by xylose transport in recombinant Saccharomyces cerevisiae. Biotechnol Bioeng 2003, 82:818-824. 
17. Van den Brink J, de Vries RP: Fungal enzyme sets for plant polysaccharide degradation. Appl Microbiol Biotechnol 2011, 91:1477-1492.

18. Culleton H, McKie V, de Vries RP: Physiological and molecular aspects of degradation of plant polysaccharides by fungi: what have we learned from Aspergillus? Biotechnol J 2013, 8:884-894.

19. Ruepp A, Zollner A, Maier D, Albermann K, Hani J, Mokrejs M, Tetko I, Güldener U, Mannhaupt G, Münsterkötter M, Mewes HW: The FunCat, a functional annotation scheme for systematic classification of proteins from whole genomes. Nucleic Acids Res 2004, 32:5539-5545.

20. Harris SD, Turner G, Meyer V, Espeso EA, Specht T, Takeshita N, Helmstedt K: Morphology and development in Aspergillus nidulans: a complex puzzle. Fungal Genet Biol 2009, 46(Suppl 1):S82-S92.

21. Wieczorke R, Krampe S, Weierstall T, Freidel K, Hollenberg CP, Boles E: Concurrent knock-out of at least 20 transporter genes is required to block uptake of hexoses in Saccharomyces cerevisiae. FEBS Lett 2009, 464:123-128.

22. Ruijter GJG, Visser J: Carbon repression in Aspergilli. FEMS Microbiol Lett 1997, 151:103-114.

23. Brown NA, de Gouvea PF, Krohn NG, Savoldi M, Goldman GH: Functional characterisation of the non-essential protein kinases and phosphatases regulating Aspergillus nidulans hydrolytic enzyme production. Biotechnol Biofuels 2013, 6:91.

24. Kubicek CP, Mikus M, Schuster A, Schmoll M, Seiboth B: Metabolic engineering strategies for the improvement of cellulose production by Hypocrea jecorina. Biotechnol Biofuels 2009, 2:6834-6848.

25. Pao SS, Paulsen IT, Saier MH Jr: Major facilitator superfamily. Microbiol Mol Biol Rev 1998, 62:1-34.

26. Andersen MR, Vongsangnak W, Panagiotou G, Salazar MP, Lehmann L, Nielsen J: A trispecies Aspergillus microarray: comparative transcriptomics of three Aspergillus species. Proc Natl Acad Sci U S A 2008, 105:4387-4392.

27. Ries L, Pullan ST, Delmas S, Malla S, Blythe MJ, Archer DB: Genome-wide transcriptional response of Trichoderma reesei to lignocellulose using RNA sequencing and comparison with Aspergillus niger. BMC Genomics 2013, 14:541-553.

28. Mach-Aigner AR, Omony J, Jovanovic B, Van Boxtel AJB, De Graaff LH: D-xylose concentration-dependent hydrolase expression profiles and the function of CreA and XInR in Aspergillus niger. Appl Environ Microbiol 2012, 78:3145-3155

29. Saloheimo A, Rauta J, Stasyk OV, Sibirny AA, Penttilä M, Ruohonen L: Xylose transport studies with xylose-utilizing Saccharomyces cerevisiae strain expressing heterologous and homologous permeases. App/ Microbiol Biotechnol 2007, 74:1041-1052.

30. Young EM, Comer AD, Huang H, Alper HS: A molecular transporter engineering approach to improving xylose catabolism in Saccharomyces cerevisiae. Metab Eng 2012, 14:401-411.

31. Nayak T, Szewczyk E, Oakley CE, Osmani A, Ukil L, Murray SL, Hynes MJ, Osmani SA, Oakley BR: A versatile and efficient gene-targeting system for Aspergillus nidulans. Genetics 2006, 172:1557-1566.

32. Fantes $\mathrm{PA}$, Roberts CF: Beta-galactosidase activity and lactose utilization in Aspergillus nidulans. J Gen Microbiol 1973, 77:417-486.

33. Tamayo EN, Villanueva A, Hasper AA, de Graaff LH, Ramón D, Orejas M: CreA mediates repression of the regulatory gene $x \ln R$ which controls the production of xylanolytic enzymes in Aspergillus nidulans. Fungal Genet Biol 2008, 45:984-993.

34. Shroff RA, O'Connor SM, Hynes MJ, Lockington RA, Kelly JM: Null alleles of creA, the regulator of carbon catabolite repression in Aspergillus nidulans. Fungal Genet Biol 1997, 22:28-38.

35. Arst HN Jr, Tollervey D, Dowzer CE, Kelly JM: An inversion truncating the creA gene of Aspergillus nidulans results in carbon catabolite derepression. Mol Microbiol 1990, 4:851-854.

36. Osmani SA, May GS, Morris NR: Regulation of the mRNA levels of nimA, a gene required for the G2-M transition in Aspergillus nidulans. I Cell Biol 1987, 104:1495-1504.

37. Sambrook J, Russel DW: In Molecular Cloning: A Laboratory Manual. Thirdth edition. Edited by Argentine J. Cold Spring Harbor, NY: Cold Spring Harbor Laboratory Press; 2001

38. Gietz RD, Schiestl RH: High-efficiency yeast transformation using the LiAc/ SS carrier DNA/PEG method. Nat Protoc 2007, 2:31-34.
39. Semighini CP, Marins M, Goldman MHS, Goldman GH: Quantitative analysis of the relative transcript levels of $A B C$ transporter atr genes in Aspergillus nidulans by real-time reverse transcription-PCR assay. Appl Environ Microbiol 2002, 68:1351-1357.

40. Colabardini AC, Brown NA, Savoldi M, Goldman MH, Goldman GH: Functional characterization of Aspergillus nidulans ypkA, a homologue of the mammalian kinase SGK. PLOS One 2013, 8:e57630.

doi:10.1186/1754-6834-7-46

Cite this article as: Colabardini et al:: Functional characterization of a xylose transporter in Aspergillus nidulans. Biotechnology for Biofuels 2014 7:46.

\section{Submit your next manuscript to BioMed Central and take full advantage of:}

- Convenient online submission

- Thorough peer review

- No space constraints or color figure charges

- Immediate publication on acceptance

- Inclusion in PubMed, CAS, Scopus and Google Scholar

- Research which is freely available for redistribution

Submit your manuscript at www.biomedcentral.com/submit
() Biomed Central 